\title{
mRNAs and Protein Synthetic Machinery Localize into Regenerating Spinal Cord Axons When They Are Provided a Substrate That Supports Growth
}

\author{
Ashley L. Kalinski, ${ }^{1 *}{ }^{\circledR}$ Rahul Sachdeva, ${ }^{2 *}{ }^{\oplus}$ Cynthia Gomes, ${ }^{3}$ Seung Joon Lee, ${ }^{3}$ Zalak Shah, ${ }^{3}$ John D. Houle, ${ }^{2}$ \\ and $\odot$ Jeffery L. Twiss ${ }^{2,3}$ \\ ${ }^{1}$ Department of Biology, Drexel University, Philadelphia, Pennsylvania 19104, ${ }^{2}$ Department of Neurobiology and Anatomy, Drexel University College of \\ Medicine, Philadelphia, Pennsylvania 19129, and ${ }^{3}$ Department of Biological Sciences, University of South Carolina, Columbia, South Carolina 29208
}

\begin{abstract}
Although intra-axonal protein synthesis is well recognized in cultured neurons and during development in vivo, there have been few reports of mRNA localization and/or intra-axonal translation in mature CNS axons. Indeed, previous work indicated that mature CNS axons contain much lower quantities of translational machinery than PNS axons, leading to the conclusion that the capacity for intraaxonal protein synthesis is linked to the intrinsic capacity of a neuron for regeneration, with mature CNS neurons showing much less growth after injury than PNS neurons. However, when regeneration by CNS axons is facilitated, it is not known whether the intra-axonal content of translational machinery changes or whether mRNAs localize into these axons. Here, we have used a peripheral nerve segment grafted into the transected spinal cord of adult rats as a supportive environment for regeneration by ascending spinal axons. By quantitative fluorescent in situ hybridization combined with immunofluorescence to unambiguously distinguish intra-axonal mRNAs, we show that regenerating spinal cord axons contain $\beta$-actin, GAP-43, Neuritin, Reg3a, Hamp, and Importin $\beta 1$ mRNAs. These axons also contain $5 S$ rRNA, phosphorylated S6 ribosomal protein, eIF2 $\alpha$ translation factor, and 4EBP1 translation factor inhibitory protein. Different levels of these mRNAs in CNS axons from regenerating PNS axons may relate to differences in the growth capacity of these neurons, although the presence of mRNA transport and likely local translation in both CNS and PNS neurons suggests an active role in the regenerative process.
\end{abstract}

Key words: axon regeneration; RNA transport; spinal cord injury; translation

Significance Statement

Although peripheral nerve axons retain the capacity to locally synthesize proteins into adulthood, previous studies have argued that mature brain and spinal cord axons cannot synthesize proteins. Protein synthesis in peripheral nerve axons is increased during regeneration, and intra-axonally synthesized proteins have been shown to contribute to nerve regeneration. Here, we show that mRNAs and translational machinery are transported into axons regenerating from the spinal cord into the permissive environment of a peripheral nerve graft. Our data raise the possibility that spinal cord axons may make use of localized protein synthesis for regeneration.

\section{Introduction}

Transport of mRNAs into and translation within subcellular sites appears to be an evolutionarily conserved mechanism that polarized eukaryotic cells use to establish and maintain the unique

Received March 30, 2015; revised May 24, 2015; accepted June 15, 2015.

Author contributions: A.L.K., R.S., J.D.H., and J.L.T. designed research; A.L.K., R.S., C.G., S.J.L., and Z.S. performed research; S.J.L. and J.D.H. contributed unpublished reagents/analytic tools; A.L.K., R.S., C.G., Z.S., and J.D.H. analyzed data; A.L.K., R.S., J.D.H., and J.L.T. wrote the paper.

This work was supported by Craig H. Nielsen Foundation Grant 224125 (J.D.H.), National Institutes of Health Grant P01-NS055976 (J.D.H., J.L.T.), and the Dr. Miriam and Sheldon G. Adelson Medical Research Foundation (J.L.T.).J.L.T. is supported by the South Carolina SmartState Endowment Program (Center for Childhood Neurotherapeutics) through the University of South Carolina.

*A.L.K. and R.S. contributed equally to this work.

The authors declare no competing financial interests. subcellular domains needed for organismal development, rapid responses to environmental stimuli, and several aspects of cellular function (Martin and Ephrussi, 2009). With the long distances that often separate synaptic terminals from the neuronal cell body, neurons rely heavily on localized protein synthesis for autonomy of these distal reaches of their cytoplasm (Jung et al., 2012). Early morphological studies indicated that ribosomes concentrate on the postsynaptic side of neurons near the base of dendritic spines (Steward and Levy, 1982), and dendritically syn-

Correspondence should be addressed to Jeff Twiss, Department of Biological Sciences, University of South Carolina, 715 Sumter Street, CLS 705, Columbia, SC 29208. E-mail: twiss@mailbox.sc.edu.

DOI:10.1523/JNEUROSCI.1249-15.2015

Copyright $\odot 2015$ the authors $\quad 0270-6474 / 15 / 3510357-14 \$ 15.00 / 0$ 
thesized proteins have been shown to contribute to synaptic function (Martin and Ephrussi, 2009). Although these initial studies failed to detect ribosomes in mature axons of the CNS, early works from several groups indicated that axons of invertebrate neurons and some vertebrate neurons contain mRNAs and translational machinery (Twiss and van Minnen, 2006). However, arguments were posited that these were unique situations in which neurons had not yet fully polarized in culture or had specialized structures and/or functionality (Kindler et al., 1997). Nonetheless, there have been an increasing number of studies pointing to the protein synthetic capacity of growing axons, with several indicating that the locally synthesized proteins contribute to varying aspects of axon growth. This has been particularly the case for neurons in the PNS, which are argued to have a high intrinsic growth capacity and locally generated proteins that contribute to regenerative growth.

PNS axons can regenerate spontaneously after injury, but those in the CNS have to be nurtured to regenerate. Growth inhibitory molecules in the CNS are known to create a nonpermissive environment for axonal regeneration in the injured brain and spinal cord (Geoffroy and Zheng, 2014). Strategies to overcome such growth inhibitory molecules have had limited success increasing regeneration by CNS axons, indicating the important role of the intrinsic growth capacity in determining success of CNS versus PNS neurons. Strategies to target such intrinsic growth mechanisms have increased in CNS regeneration research, with some providing a means to support growth in the nonpermissive environment of the injured CNS (Park et al., 2008; Liu et al., 2010; Hellal et al., 2011; Sun et al., 2011). Proteins that are synthesized locally in axons provide an intrinsic growth mechanism for regeneration in the PNS, both initiating retrograde signaling for increasing axon growth programs and acting locally to facilitate axon extension (Perry and Fainzilber, 2014). Application of CNS growth inhibitory molecules to cultured dorsal root ganglion (DRG) neurons was shown to actively decrease axonal levels of $\beta$-actin mRNA that supports axon growth (Willis et al., 2007), indicating that the extrinsic environment that the axon encounters can alter this intrinsic growth mechanism of localized protein synthesis.

The possibility that mature CNS axons might have protein synthetic capacity has received less attention. Verma et al. (2005) showed that CNS axons in the adult rodent optic nerve have very low levels of translational machinery compared with those in the sciatic nerve (Verma et al., 2005). These authors hypothesized that axonal levels of translational machinery are linked to their intrinsic growth capacity, with the overall lower growth capacity of CNS neurons predicting a lower content of the translational machinery that is needed for intra-axonal protein synthesis. However, recent work suggests that intra-axonal translation may be activated in some mature CNS neurons (Baleriola et al., 2014). Here, we show that ascending spinal cord axons, which normally show limited regenerative potential, contain both mRNAs and translational machinery when they are provided the growth supportive environment of a peripheral nerve graft (PNG). Moreover, the percentage of mRNA containing axons for some regeneration-associated gene (RAG) products is overall comparable with what is seen in the regenerating sciatic nerve axons, suggesting that mechanisms for targeting mRNAs into axons is retained in the CNS.

\section{Materials and Methods}

Animal use and survival surgery. Sprague Dawley rats (175-250 g) were used for all experiments. Both male and female rats were used for periph- eral nerve injury, whereas only female rats were used for spinal cord injury and peripheral nerve grafting. Isoflurane was used for anesthesia in all cases (5\% for induction and $2-3 \%$ for maintenance). For peripheral nerve injury, anesthetized rats were subjected to a unilateral sciatic nerve crush at mid-thigh as described previously (Twiss et al., 2000); the contralateral nerve served as an uninjured (naive) control. Seven days after injury, these animals were killed by asphyxiation with $\mathrm{CO}_{2}$. L4-L5 DRGs were removed for dissociated culture (see below) or removed and immersion fixed in $2 \%$ paraformaldehyde for $2 \mathrm{~h}$, followed by overnight cryoprotection in 30\% sucrose. Sciatic nerves from mid-thigh were similarly immersion fixed and cryoprotected.

To generate a "pre-degenerated" peripheral nerve for grafting, tibial nerves of anesthetized "donor" rats were cut bilaterally. After $7 \mathrm{~d}$ to allow for Wallerian degeneration, nerves distal to the transection were harvested and used as grafts for "recipient" spinal cord transected rats. For this, donor rats were anesthetized using ketamine $(60 \mathrm{mg} / \mathrm{kg})$ and xylazine $(10 \mathrm{mg} / \mathrm{kg})$, and pre-degenerated tibial nerve ( $\sim 8 \mathrm{~mm}$ in length) was harvested. To prevent graft rejection, recipient rats received daily subcutaneous cyclosporine A $(10 \mathrm{mg} / \mathrm{kg})$ beginning $3 \mathrm{~d}$ before grafting and continuing for 2 weeks, at which time we changed to oral dosing (1 $\mathrm{mg} / \mathrm{ml}$ in drinking water). These animals also received ampicillin (200 $\mathrm{mg} / \mathrm{kg})$ and buprenorphine $(0.1 \mathrm{mg} / \mathrm{kg})$ at the time of surgery. For spinal cord injury, the cord was exposed by dorsal laminectomy for access to the T12 segment of the cord. A 2-3 mm complete spinal cord transection was made by vacuum aspiration using a glass micropipette. The PNG was secured to dura mater using 10-0 suture, and one end was apposed to the caudal wall of the lesion cavity and the distal end was left unapposed, lying on top of adjacent vertebral bodies. After 3 weeks, grafted rats were killed using intraperitoneal injection of Euthasol (pentobarbital sodium and phenytoin sodium) and transcardial perfusion with $2 \%$ paraformaldehyde. Graft tissues were then postfixed in $2 \%$ paraformaldehyde overnight and cryoprotected in 30\% sucrose solution before cryostat sectioning. Grafts were cut longitudinally at $10 \mu \mathrm{m}$ thickness and mounted directly on glass slides for staining procedures.

Cell culture. For primary neuronal cultures, L4-L5 DRG were harvested in Hybernate-A medium and then dissociated using type I collagenase ( $50 \mathrm{U} / \mathrm{ml}$; Gibco) for $15 \mathrm{~min}$ at $37^{\circ} \mathrm{C}, 5 \% \mathrm{CO}_{2}$ (Twiss et al., 2000). Dissociated ganglia were cultured overnight on laminin/poly-L-lysinecoated coverslips. For in situ hybridization (see below), coverslips were fixed for $15 \mathrm{~min}$ in buffered 2\% paraformaldehyde (Willis et al., 2007).

RNA isolation and analyses. For isolation of RNA from DRGs, L4-L5 ganglia were harvested and rinsed in DMEM/F-12 medium with $1 \times \mathrm{N} 2$ supplement (Sigma), 10\% fetal bovine serum (Life Technologies), $2 \mathrm{~mm}$ L-glutamine, and $80 \mathrm{~nm}$ of the RNA polymerase inhibitor 5,6dichlorobenzimidazole riboside (Sigma). DRGs were dissociated with 50 $\mathrm{U} / \mathrm{ml}$ collagenase as above, gently triturated, and then pelleted at $2500 \times$ $g$ for $2 \mathrm{~min}$. Dissociated ganglia were then processed directly for RNA isolation using the RNAqueous total kit (Ambion). RNA concentration was determined using the Ribogreen reagent (Invitrogen). Eighty nanograms of RNA were reverse transcribed using iScript (Bio-Rad). Digital droplet PCR (ddPCR) was performed on a QX200 instrument (Bio-Rad) using predesigned Taqman primer/probes for rat Reg3a, Hamp, Importin $\beta 1$, and Amphoterin (also called Hmgb1) mRNAs (Integrated DNA Technologies). Reg3a, Hamp, and Importin $\beta 1$ were duplexed with rat Amphoterin mRNA primers/probes for normalization.

In situ hybridization. Fluorescence in situ hybridization combined with immunofluorescence (FISH/IF) was used to detect and quantitate axonal mRNAs. This was performed using digoxigenin (DIG)-labeled antisense, oligonucleotide probes. Probes were designed using Oligo 6 software (Molecular Biology Insights) and tested for specificity by BLASTN against GenBank for rat entries. Antisense probes for $\beta$-actin, GAP-43, Neuritin (Nrn1), and Importin $\beta 1$ mRNAs have been published previously (Willis et al., 2007; Merianda et al., 2013b). Other antisense probes consisted of the following: Hamp (GenBank accession number NM_053469), nucleotides 150-195 and 276-322; and, Reg3a variant 1 (GenBank accession number NM_172077), nucleotides 326-372 and 415-461. Note that the Reg3a probes used here will also detect variant 2 (nucleotides 224-270 and 313-359 in GenBank accession number NM_001145846). For specificity control, a DIG-labeled scrambled probe 
was used. Hybridization conditions were as described previously (Vuppalanchi et al., 2010) with minor modifications. A probe at $50 \mu \mathrm{g} / \mathrm{ml}$ was used for cultured neurons, and $120 \mu \mathrm{g} / \mathrm{ml}$ was used for tissue sections. Also, some probes showed higher specificity if hybridization was performed after immunolocalization. In these cases, DIG-labeled probes were added to tissues after incubation with secondary antibodies for proteins, followed by incubation with anti-DIG primary and secondary antibodies. $\beta$-actin, Nrn1, and GAP-43 probes were handled in this way. In all cases, quantitation of signals (see below) was performed on tissues that were handled in an identical manner, and only intra-probe comparisons were performed for any probe set.

Primary antibodies used were as follows: anti-neurofilament heavy chain (NFH; 1:750 for tissue and 1:1000 for culture; Millipore); anti-NF medium chain (NFM; 1:200 for tissue; Millipore); anti-NF light chain (NFL; 1:400 for tissue; Aves); anti-SCG10 (1:500 for tissue; Novus Biologicals); anti-DIG (1:200; Jackson ImmunoResearch); and Cy3 antiDIG (1:200; Jackson ImmunoResearch). Secondary antibodies used were as follows: FITC donkey anti-chick; Cy3 donkey anti-mouse; FITC donkey anti-rabbit (1:200 for all; Jackson ImmunoResearch); and Alexa Fluor 488 goat anti-rabbit (1:750; Invitrogen). All FISH/IF analyses were performed on at least three biological replicates per group with quantifications as outlined below.

Immunostaining. IF on tissue sections was performed as described previously (Merianda et al., 2013b). Primary antibodies used included the following: anti-NFH (1:750; Millipore); anti-NFM (1:200; Millipore); anti-NFL (1:400; Aves Labs); Y10B anti-5.8S rRNA (1:1000; Abcam); anti-S6 ${ }^{\mathrm{PS} 235 / \mathrm{S} 236}$ (1:100; Cell Signaling Technology); antieukaryotic translation factor $2 \alpha$ (eIF2 $\alpha$ ) and anti-eIF $2 \alpha^{\text {PS51 }}$ (1:100 for both; Cell Signaling Technology); and anti-eukaryotic factor $4 \mathrm{E}$ binding protein 1 (4EBP1) and anti-4EBP1 ${ }^{\text {PT37/PT36 }}(1: 100$ and 1:500, respectively; Cell Signaling Technology). Secondary antibodies used were as follows: FITC donkey anti-chick, Cy5 donkey anti-rabbit, Cy3 goat antimouse, and Cy5 donkey anti-mouse (1:200 for all; Jackson ImmunoResearch); and Alexa Fluor 488 goat anti-rabbit (1:750; Invitrogen). All IF analyses were performed on at least three biological replicates per group.

Imaging of axonal mRNA signals. For cultured DRG neurons, coverslips were imaged by epifluorescence using a Zeiss Axioplan inverted microscope fitted with a Hamamatsu ORCA-ER CCD camera. After first normalizing acquisition parameters so that any background signals from scrambled probes and antibody detection were not included, exposurematched images were acquired using SlideBook software (Intelligent Imaging Innovations). Raw .tiff images were used for calculating FISH signal intensities using NIH ImageJ (http://imagej.nih.gov/ij/) along a $50 \mu \mathrm{m}$ segment of mid-axon shaft. The higher FISH signals in cell body compared with axons required lower exposure parameters such that axonal and cell body intensities are not comparable. Representative images of axonal segments were aligned using the Straighten plug-in for NIH ImageJ.

Confocal microscopy was used to image tissue sections of sciatic nerve and PNGs. Scanning parameters were matched between individual FISH probes for naive sciatic nerve, crushed sciatic nerve, and PNG (i.e., laser energy, pinhole, PMT gain/offset). As with the epifluorescent imaging above, acquisition parameters were normalized by first imaging the scrambled probe to assign parameters that would not acquire any nonspecific signals from the scrambled probe and fluorescent antibodies; scanning parameters for antisense probes were always set to below those generating minimal signal for the DIG-labeled scramble probe. Imaging sequences for tissues consisted of acquiring a 300-400 $\mu \mathrm{m}$ segment of nerve or PNG by taking tile $x y z$ image stacks with $63 \times$ oil-immersion objective (1.4 numerical aperture) for 12-15 optical planes at $z$ depth of $3.77-4.5 \mu \mathrm{m}(0.29 \mu \mathrm{m}$ interval between planes). This $x y z$ tile scan sequence was captured at two locations along each nerve section. The RG2B plug-in (http://rsb.info.nih.gov/ij/plugins/rg2bcolocalization. $\mathrm{html}$ ) for NIH ImageJ was used to extract RNA signals from FISH probes that overlap with axonal markers (SCG10 and NF) in each $z$ plane of the $x y z$ tile scans, with the extracted "axon-only" signal projected as a separate channel. We used several different methods to quantify the axonal FISH signals, with all analyses performed on the individual optical planes.
First, to gain an estimate of relative distribution of RNA granules in axons, the FISH signal intensities were quantified along the length of individual axons. For this, we used axons that could be optically isolated contiguously over at least $160 \mu \mathrm{m}$ in the $x$ dimension of the above $x y z$ tile scans. NIH Image J was used to quantify the intensity of these signal aggregates in region-of-interest bins across the $x$-axis over the length of the isolated axon segment.

Second, to gain an estimate of the amount of axonal mRNA in the nerve and PNG, absolute signal intensity was quantified in each $x y$ plane of the RG2B extracted images for axonal FISH signals. FISH signal intensities across the individual $x y$ planes were then normalized to the area for SCG10 plus NF immunoreactivity to account for varying amounts of axons in the nerve and PNGs between animals and experimental conditions. The relative mRNA signal intensity was averaged for all tiles in each biological replicate.

Third, to gain an estimate of the number of axons containing mRNA, we counted the absolute number of axons containing clear RNA granules across the individual optical planes of the $x y z$ tile scans. Only axons of at least $40 \mu \mathrm{m}$ in length across the tile scan were considered in this. At least 50 axon segments of each nerve/PNG section were scored to generate a percentage of "RNA-containing axons" in each nerve/PNG section, with two sections per animal to generate an average for each nerve/PNG.

Statistical analyses. Kaleidagraph software package (Synergy) was used for statistical analyses. One-way ANOVA was used to compare means of independent groups. These included fluorescent intensities from FISH using NIH ImageJ and percentage of axons with RNA granules using Volocity software. $p$ values of $\leq 0.05$ were considered as statistically significant.

\section{Results}

\section{Reg $3 a$ and Hamp mRNAs increase in axons after injury conditioning}

Ben-Yaakov et al. (2012) showed previously that Reg3a and Hamp mRNAs are regulated transcriptionally in L4-L5 DRGs after sciatic nerve injury through a STAT3 $\alpha$-dependent mechanism. At a single-gene level, Reg3a was seen to increase with peripheral nerve inflammation and after transection (He et al., 2010). Microarrays of axonal RNAs from cultured neurons suggested the presence of these mRNAs in axons (data not shown), so we used FISH/IF to determine whether we could visualize these mRNAs in the axons of cultured adult DRG neurons. For this, we used L4-L5 DRG neurons and compared axonal levels of Reg3a, Hamp, and Importin $\beta 1 \mathrm{mRNAs}$ in naive and $7 \mathrm{~d}$ injuryconditioned neurons. Each mRNA was detected in growing sensory axons and showed granular signals by FISH analyses (Fig. $1 A-C)$. Using exposure-matched images in which each experiment was normalized to DIG-labeled scramble probes, axonal levels of both Reg3a and Hamp mRNA were increased significantly in the $7 \mathrm{~d}$ injury-conditioned compared with naive DRG neurons (Fig. $1 D, E$ ). Axonal Importin $\beta 1$ mRNA levels showed no significant differences between the injury-conditioned and naive cultures (Fig. $1 F$ ).

The increase in axonal Reg3a and Hamp mRNA levels could result from a shift in subcellular localization or an overall increase in the amount of these mRNAs available for localization. Using transcript-specific RT-ddPCR, we saw significantly increased levels of Reg3a and Hamp mRNAs in the L4-L5 DRGs within $3 \mathrm{~d}$ after mid-thigh sciatic nerve crush injury (Fig. $2 A, B$ ). This is consistent with previous microarray data from Ben-Yaakov et al. (2012), and both mRNAs showed a trend to greater levels in the DRGs ipsilateral to the crush injury up to $28 \mathrm{~d}$ after crush by our RT-ddPCR analyses (Fig. $2 A, B$ ). Importin $\beta 1$ mRNA, which encodes a retrograde injury signaling protein in the DRGs and is translationally regulated in axons after crush injury (Hanz et al., 2003), showed no significant changes from naive in the L4-L5 
A

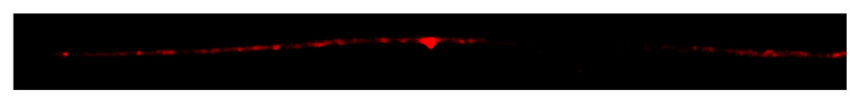

Reg3a mRNA (red)

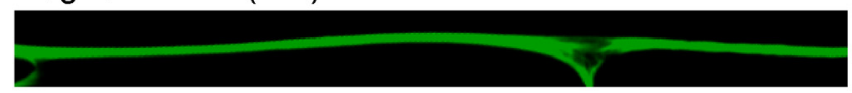

$\mathrm{NF}$ (green)

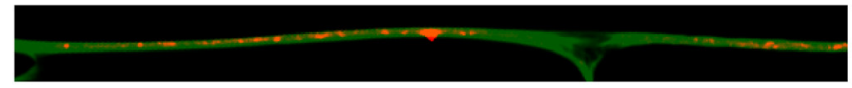

Reg3a mRNA (red), NF (green)

B

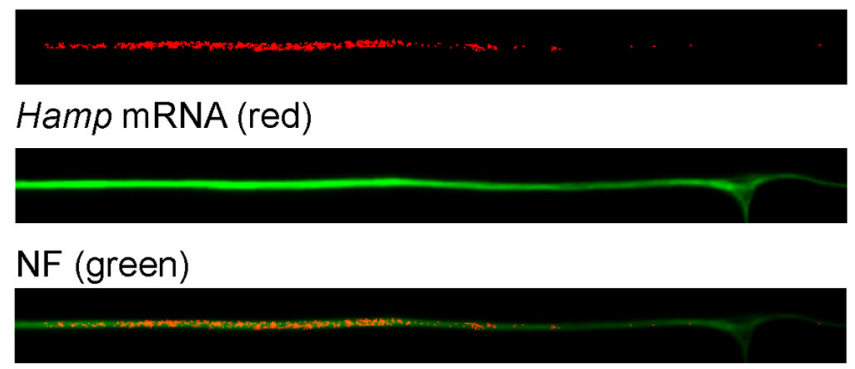

Hamp mRNA (red), NF (green)

C

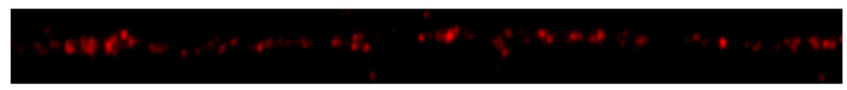

Importin $\beta 1$ mRNA

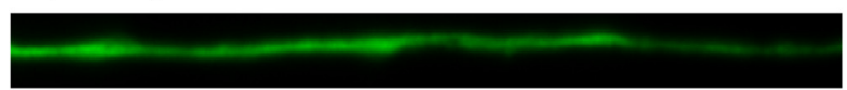

NF (green)

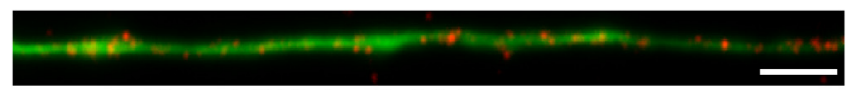

Importin $\beta 1$ mRNA (red), NF (green)

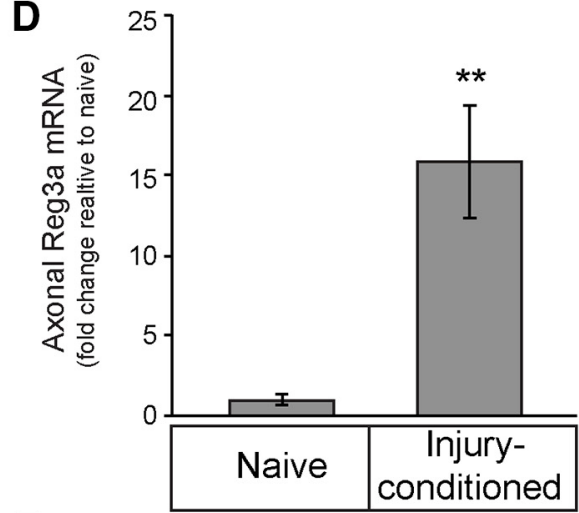

$\mathbf{E}$

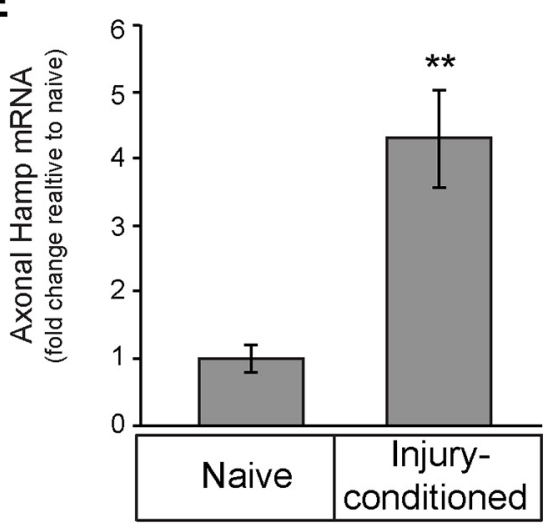

$\mathbf{F}$

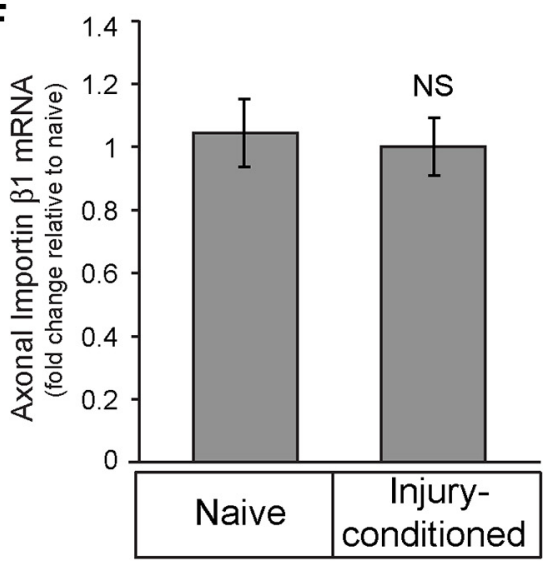

Figure 1. Injury-conditioned DRG neurons show increased axonal levels of Reg3a and Hamp mRNAs in culture. $\boldsymbol{A}-\boldsymbol{C}$, Representative FISH/IF images for Reg3a $(\boldsymbol{A})$, Hamp (B), and Importin $\beta 1$ ( $\boldsymbol{C}$ ) mRNAs (red) and NF protein (green) in the mid-axon shaft of L4-L5 DRGs cultured $7 \mathrm{~d}$ after sciatic nerve crush injury are shown. Scale bar, $5 \mu$ m. $D$-F, Quantitation of intra-axonal RNA FISH signals for L4 -L5 DRG cultures prepared $7 \mathrm{~d}$ after sciatic nerve crush (injury-conditioned) versus uninjured (naive) is shown. Data are expressed as fold change relative naive axon signals \pm SEM ( $n \geq 30$ axons over three separate culture experiments; ${ }^{* *} p \leq 0.001$; NS, not significant by one-way ANOVA.

DRGs after crush injury (Fig. 2C). The increased transcription of Reg $3 a$ and Hamp after axotomy plus their axonal localization of their mRNAs suggest that the REG3A and Hepcidin proteins encoded by these mRNAs may contribute to axonal growth.

\section{Reg3a and Hamp mRNAs localize into PNS axons in vivo}

Levels of several mRNAs in axons of DRG neurons have been shown to increase with injury (Gumy et al., 2011; Merianda et al., 2013a,2013b; Yoo et al., 2013). The increased axonal localization described above for cultured neurons could indicate that injuryinduced transcription of some RAGs is coupled to anterograde transport of their mRNAs into axons. We used quantitative FISH/IF methods to determine whether axonal transport of Reg3a and Hamp mRNAs might also increase in vivo. In the
FISH/IF studies above, Reg3a, Hamp, and Importin $\beta 1$ mRNAs were not restricted to neurons, and signals were seen in the nonneuronal cells of the DRG cultures (data not shown). Because these non-neuronal signals would complicate any in vivo quantitation of axonal mRNA in the nerve, we sought an approach to restrict our quantitation to only FISH signals that overlapped with the axonal markers in individual planes of confocal image stacks. For this, we used post-processing with the RG2B NIH ImageJ plug-in to extract the overlapping FISH signals. In this way, a third channel that removed any FISH signals that did not overlap with the immunoreactivity from NF and SCG10 formed a channel of axon-only FISH signals for each optical plane and tile (Fig. $3 A, B$ ). By applying this image processing approach to highmagnification images obtained by tile scanning, we are able to 

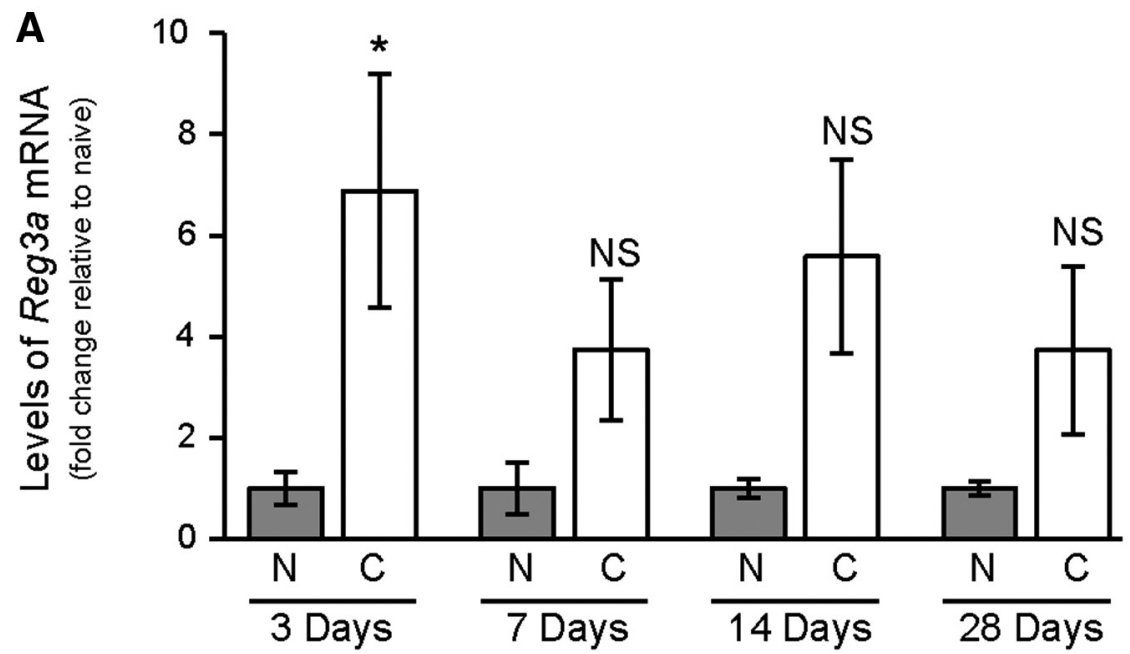

B

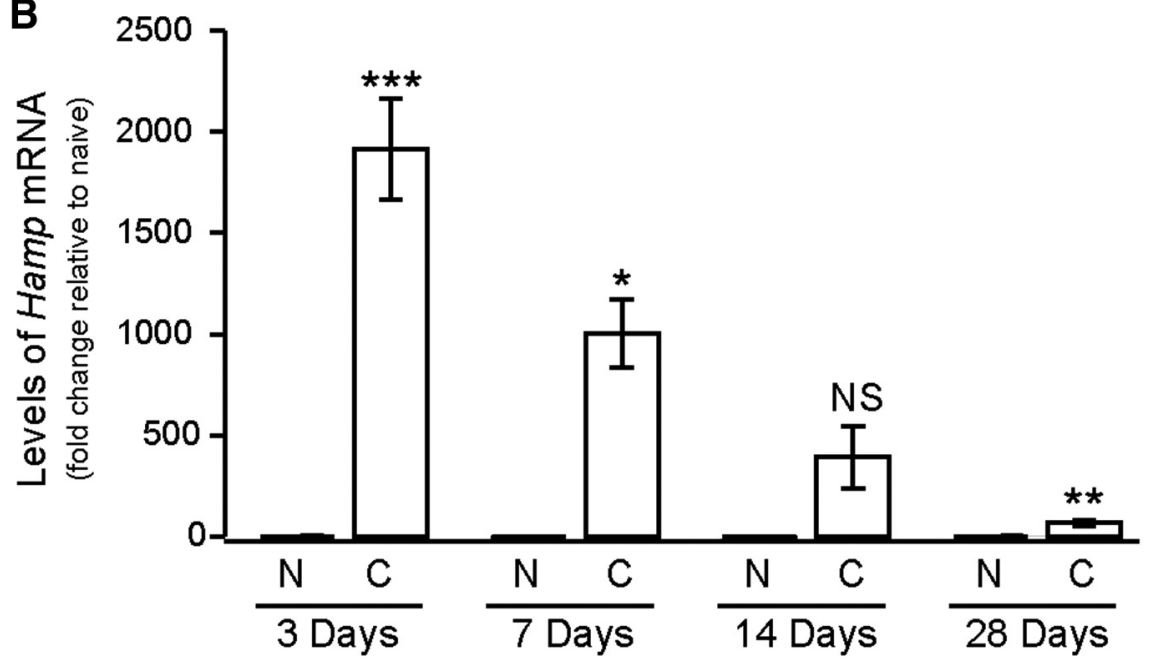

C

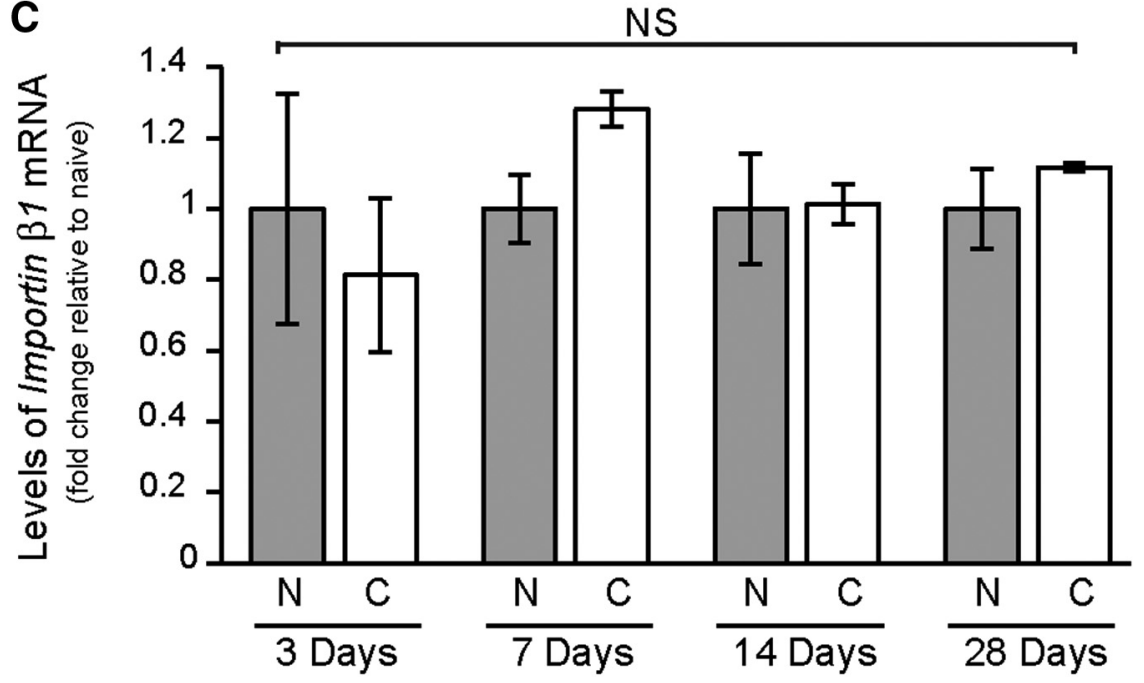

Figure 2. Reg3a and Hamp mRNAs levels in DRGs are increased after peripheral nerve injury. RT-ddPCR results for $\operatorname{Reg} 3 a(\boldsymbol{A})$, Hamp (B), and Importin $\beta 1$ (C) mRNA levels in L4-L5 DRGs at 3-28 d after sciatic nerve crush are shown. Injured DRGs (white columns) are expressed as fold change relative to the contralateral, uninjured DRGs (gray columns). Error bars represent \pm SEM for matched L4 -L5 DRGs taken ipsilateral and contralateral to the injured sciatic nerve from individual animal subjects $(n=3)$. Reg $3 a$ and Hamp mRNAs show a significant increase in cell body levels after $3 \mathrm{~d}$ sciatic nerve injury, whereas there is no significant change in /mportin $\beta 1$ mRNA levels. ${ }^{*} p \leq 0.05,{ }^{* *} p \leq 0.001,{ }^{* * *} p \leq 0.0001$; NS, not significant by one-way ANOVA. C, Crushed; N, naive. selectively visualize axonal RNA granules over a $300 \times 400 \mu \mathrm{m}$ segment of peripheral nerve (Fig. $3 A, C$ ). The resulting axon-only FISH/IF image from the sciatic nerve shown in Figure $3 B$ clearly displays RNA signals that are not evenly distributed along the axon or evenly distributed between axons in these sciatic nerve sections. It should be noted that RG2B processed image does not provide raw RNA intensity but rather an intensity that is normalized for the NF plus SCG10 signal intensity; thus, the axon-only FISH channel also provides an internal normalization parameter to account for changes in NF plus SCG10 signal intensities across the individual images of these $x y z$ tile scans and different nerve and experimental preparations.

Optically isolating individual axons from the $x y z$ stacks from the imaging sequences as shown in Figure 3 enabled us to visualize granular profiles for the RNA signals in the processed axon-only RNA channels and perform orthogonal projections to validate intra-axonal nature of the signals. Granular FISH signals for Reg3a, Hamp, and Importin $\beta 1$ mRNAs were clearly visible in optically isolated axons of both the naive and crushed sciatic nerve by $x y z$ and $y z$ imaging (Fig. 4). Moreover, both Reg3a and Hamp mRNAs appeared more abundant in the $7 \mathrm{~d}$ crush nerve compared with naive nerve sections (Fig. $4 A, B, D, E)$. This initial analysis provides an in vivo correlation with the in vitro culture data, suggesting that levels of Reg3a and Hamp mRNAs are increased in regenerating axons. Quantitation of the intraaxonal signal intensities for Reg3a, Hamp, and Importin $\beta 1 \mathrm{mRNAs}$ confirm this impression as detailed below (see Fig. 6).

Reg $3 a$ and Hamp mRNAs localize into PNG axons after spinal cord transaction

DRG levels of Reg3a and Hamp mRNAs were shown to increase after contusion of the spinal cord, despite injured central DRG branches showing little spontaneous regeneration after dorsal column injury (Blesch et al., 2012). Thus, we asked whether Reg3a and Hamp mRNAs might be transported into regenerating axons in the spinal cord. For this, we used a spinal cord transection injury model coupled with PNG that supports robust regeneration of injured sensory axons in spinal cord (Côté et al., 2011). The PNG sections showed many fine- and medium-caliber axons that required a mixture of $\mathrm{NF}$ and SCG10 antibodies for optimal visualization (Fig. 5A,C). FISH signals for both Reg3a 
A

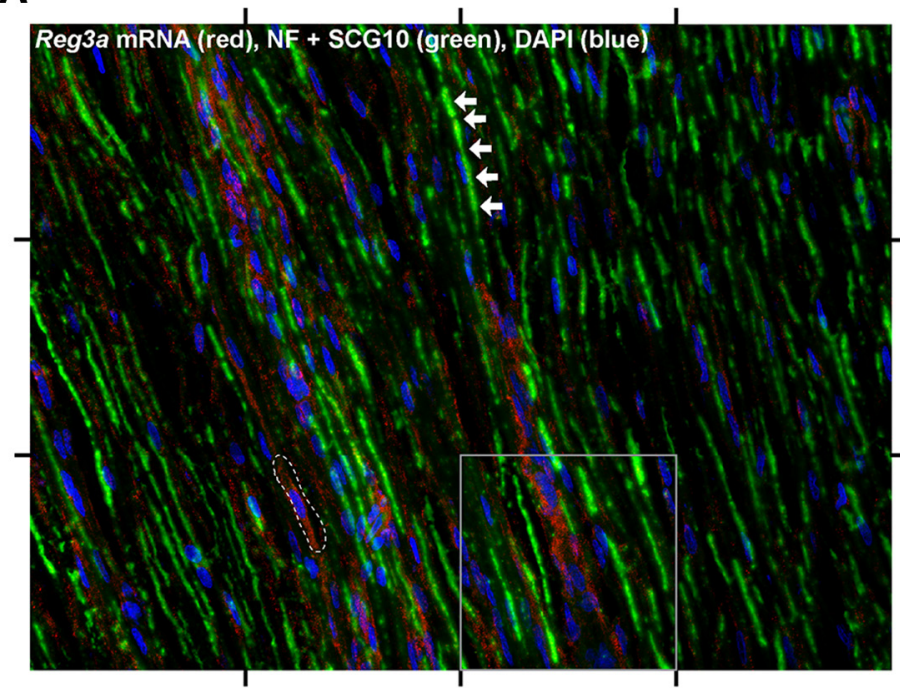

C

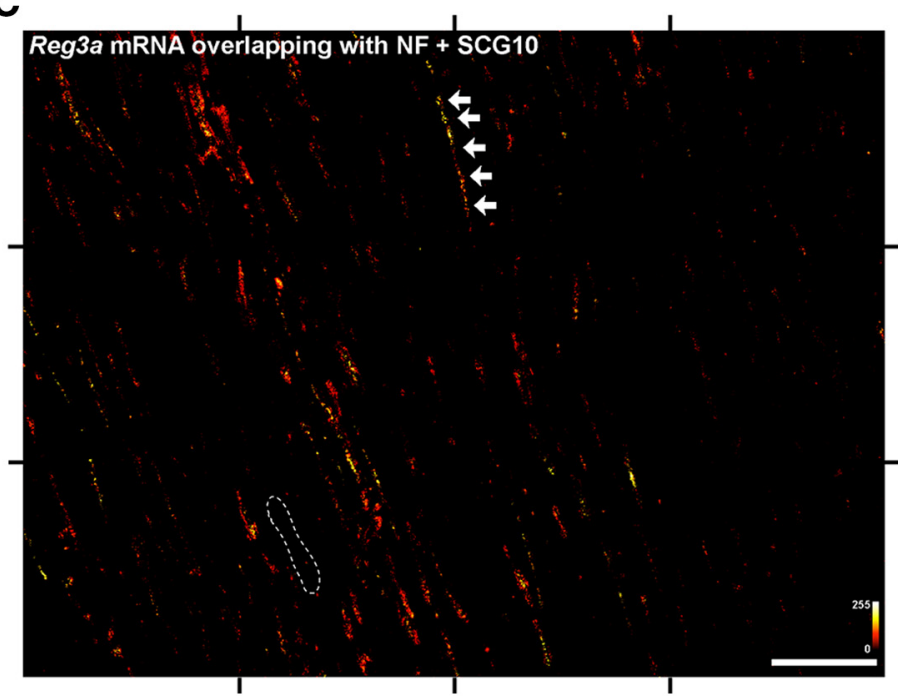

B

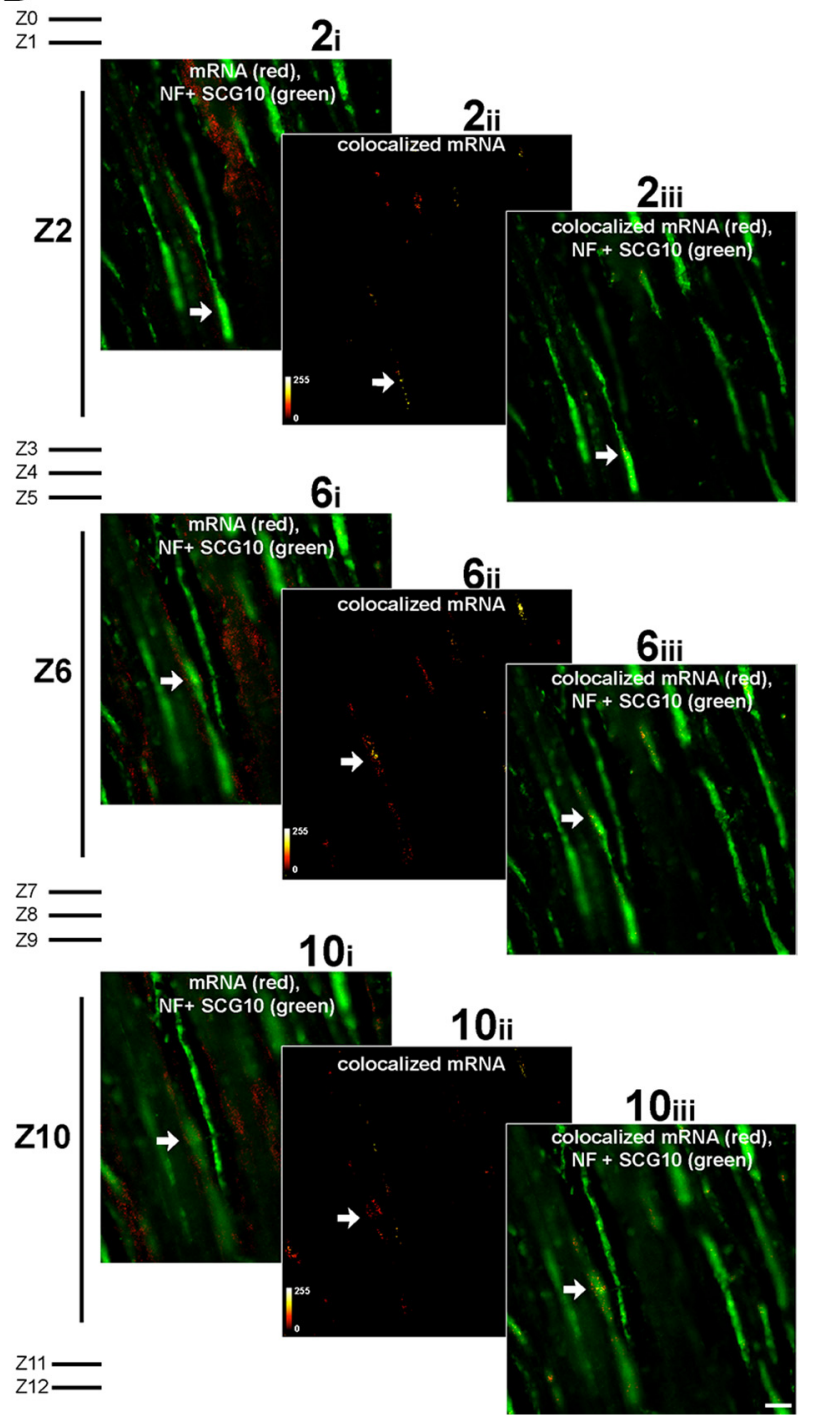

Figure 3. Spatial distribution of Reg3a mRNA in sciatic nerve axons. Sequence of confocal imaging and post-processing pipeline for sciatic nerve sections that were used to selectively visualize mRNA in axons of nerve tissues is shown. $A$, Representative xyz projection from $3 \times 4$ tile scan $(103 \times 103 \mu \mathrm{m}$ each) is shown. This xyz image was created from 12 optical planes taken across a $z$ distance of $3.77 \mu \mathrm{m}$ (step size, $0.29 \mu \mathrm{m}$ ) as individual xyz tiles that were stitched together into a montage. Reg3a mRNA is shown in red, NF plus SCG10 proteins are shown in green, and DAPI signal is shown in blue. Arrows indicate axonal mRNA signal, and the dotted circle indicates what appears to be non-neuronal mRNA signal. The gray box indicates the tile that is illustrated in $\boldsymbol{B}$. $\boldsymbol{B}, 2 \mathbf{2}-\mathbf{2 i i i}$, 6i- $6 \mathbf{i i i}$, and 10i-10iii show individual xy planes from $A$ showing the sequence of post-processing to extract the axon-only mRNA FISH signals (2, 6, and 10 indicate the $Z$ stack position). $2 \mathbf{i}$, $6 \mathbf{i}$, and 10i show the original xy plane that was subjected to RG2B NIH ImageJ plug-in processing. 2ii, 6ii, and 10ii show the extracted axon-only mRNA signal in the indicated intensity spectrum. 2iii, 6iii, and 10iii show the extracted axon-only Reg3a mRNA signal (intensity spectrum as ii series) merged with the original NF plus SCG10 (green) channels. Arrows in the 2i-2iii, 6i- 6iii, and 10i-10iii image sequences indicate the same axon. C, Subtracted axon-only Reg3a mRNA signal from all tiles in which each optical plane was subtracted individually to control for varying NF plus $S C G 10$ signals is shown as an intensity spectrum. The arrows and circle indicate the same regions of the montage image as highlighted in $\boldsymbol{A}$. Scale bars: $\boldsymbol{A}, \boldsymbol{C}, 50 \mu \mathrm{m} ; \boldsymbol{B}, 10 \mu \mathrm{m}$.

and Hamp mRNAs were clearly visible in the grafts, and a proportion of the PNG FISH signals appeared to overlap with the NF plus SCG10 signals (Fig. 5A-D). Subtracting the non-neuronal RNA signals as performed above showed clear linear profiles of high FISH signal intensity in the PNG sections that overlapped.

On close inspection of the linear FISH signal arrays, it was clear that the distribution of the RNA signals varied across NF plus SCG10-immunoreactive axons with focal concentrations of higher signal intensity. Thus, we quantified the intra-axonal RNA signal intensity along contiguous $160 \mu \mathrm{m}$ axon segments from the axon-only FISH signal channel merged with the NF plus SCG10 channel in $20 \mu \mathrm{m}$ bins across the $x$ dimension. Both Reg $3 a$ and Hamp mRNAs showed clear foci of high pixel intensity along the axon with peaks that varied between individual axons (Fig.
$5 E, F)$. Importin $\beta 1$ mRNA showed axonal localization in the PNGs with approximately the same distribution (data not shown). These focal concentrations of axonal FISH signal intensities could represent aggregates of transported ribonucleoprotein particle granules or regions of translation. Qualitative analyses of caudal spinal cord immediately adjacent to the PNG showed similar granular profiles of axonal mRNA FISH signals (data not shown), which would be consistent with transport of mRNAs from spinal cord into the PNG along axons.

Axons regenerating into ascending PNG in spinal cord contain comparable levels of mRNAs as peripheral nerve High-magnification FISH/IF images from single tiles of the $x y z$ montages as in Figure 5 showed clear granular signals for Reg3a 
A

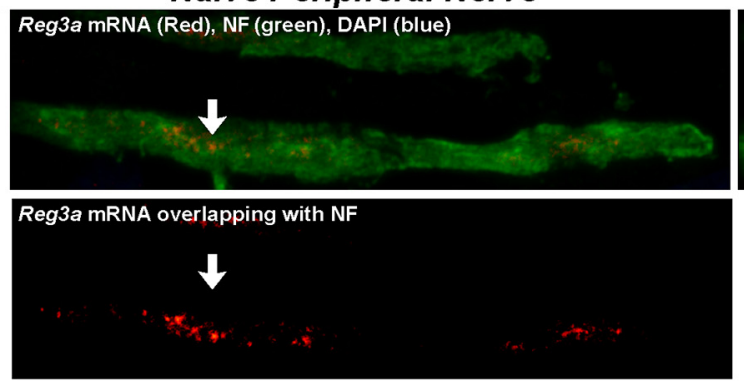

B

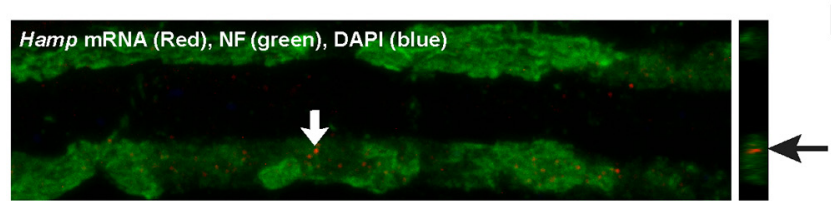

Hamp mRNA overlapping with NF

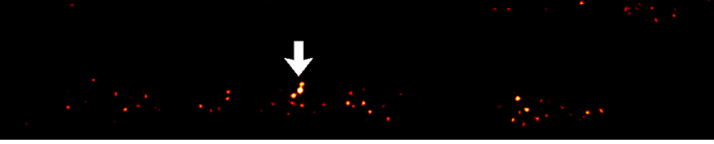

C

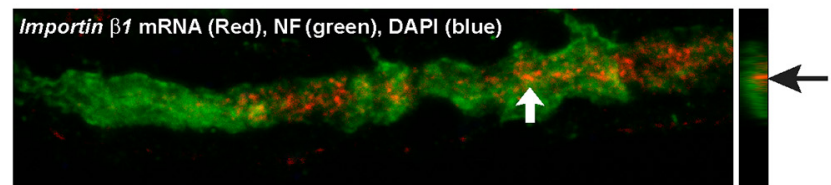

Importin $\beta 1$ mRNA overlapping with NF

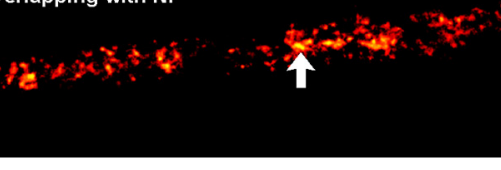

\section{D}
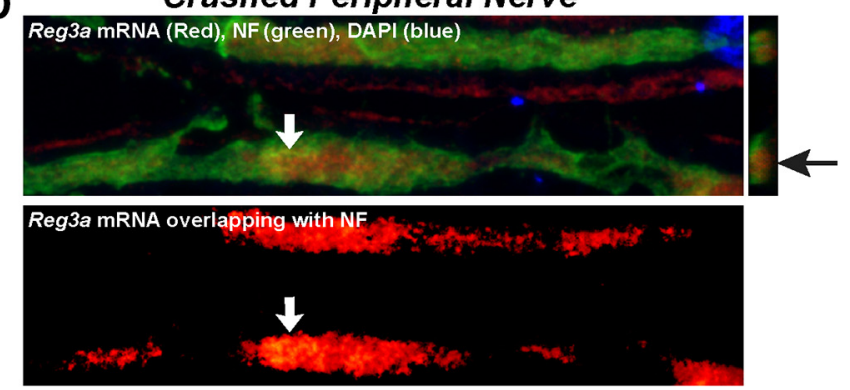

$\mathbf{E}$

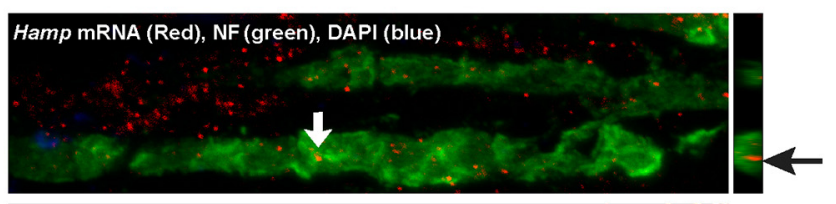

Hamp mRNA overlapping with NF

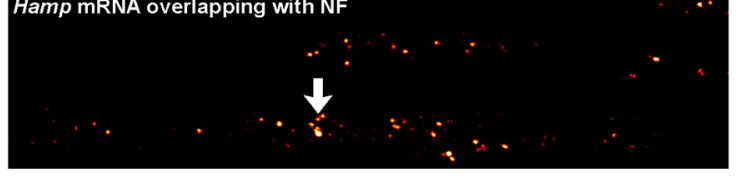

$\mathbf{F}$
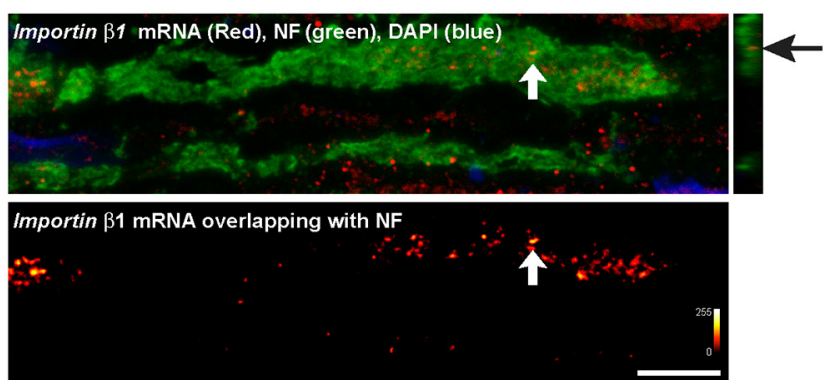

Figure 4. Reg3a and Hamp mRNAs localize to PNS axons in vivo. Representative confocal images from naive $(\boldsymbol{A}-\boldsymbol{C})$ and $7 \mathrm{~d}$ post-crush injured $(\boldsymbol{D}-\boldsymbol{F})$ sciatic nerves are shown for Reg 3 a $(\boldsymbol{A}, \boldsymbol{D})$, Hamp $(\boldsymbol{B}, \boldsymbol{E})$, and Importin $\beta 1(\boldsymbol{C}, \boldsymbol{F})$ mRNAs. Each image set for $\boldsymbol{A}-\boldsymbol{F}$ shows projected $x y z$ (top left), corresponding orthogonal $y z$ projection (top right), and projected $x y z$ of subtracted axon-only mRNA signals. The top image pairs for $\boldsymbol{A}-\boldsymbol{F}$ show mRNA in red, NF protein in green, and DAPl in blue. The subtracted axon-only panels show the RNA as an intensity spectrum as indicated. These xyz projections were constructed from eight optical planes taken at $0.29 \mu \mathrm{m} Z$-step intervals. Optically isolated axon segments across the $Z$ stacks, in which only planes corresponding to the axoplasm of the indicated axon (arrows) are projected in the xyz panels; arrows in the yz projections indicate the same axon. Scale bar, $10 \mu \mathrm{m}$.

and Hamp mRNAs in optically isolated axons (Fig. 6A,B). Importin $\beta 1$ mRNA showed similar granular signals overlapping with NF plus SCG10 signals in the PNG sections (Fig. 6C). Orthogonal $y z$ projections confirmed that the FISH signals for these transcripts resided in the axoplasm rather than in the nonneuronal cells included in optical planes from above or below the axoplasm (Fig. 6A-C, right insets).

Because Reg3a, Hamp, and Importin $\beta 1$ mRNAs localized into the axons regenerating into PNGs, we sought to directly compare the intra-axonal levels of these mRNAs in the naive sciatic nerve, regenerating sciatic nerve, and regenerating CNS axons. For this, we used Z stacks of $300 \times 300 \mu \mathrm{m}$ tile scans taken at two separate intervals along the sciatic nerve and PNG sections and generated "axon-only" FISH channels to measure the RNA signal intensity. The pixels per square micrometer of FISH signal was then normalized to area of the NF plus SCG10 signals averaged across the optical planes. The intensities for "axon-only" Reg3a, Hamp, and Importin $\beta 1 \mathrm{mRNA}$ signals were not statistically different when comparing naive sciatic nerve, $7 \mathrm{~d}$ injured sciatic nerve, or $21 \mathrm{~d}$ spinal cord PNGs (Fig. 6D-F). However, Reg3a and Hamp mRNAs showed higher-intensity signals in injured sciatic nerve compared with naive sciatic nerve injury paralleling the observations in the DRG cultures. Reg3a and Importin $\beta 1$ mRNA signal intensities trended toward being higher in the PNGs than in the injured sciatic nerve.

Because we had seen significant variability in RNA foci along the length of individual axons in Figure 5 with not all axons containing appreciable FISH signals, we determined the percentage of axons per montage image that contained RNA signals using the axon-only FISH channel merged with the NF plus SCG10 channel. Only axonal segments that were $\geq 40 \mu \mathrm{m}$ in length across the $\mathrm{Z}$ stacks were assessed. Both Reg3a and Hamp mRNAs showed significantly higher percentage of mRNA-containing axons in the $7 \mathrm{~d}$ injured versus naive sciatic nerve (Fig. 6G,H). The percentage of Reg3a mRNA-containing axons was also significantly more in the PNG than in the naive nerves, but this was not the case for Hamp mRNA in which a significantly higher percentage of RNA-containing axons was seen in the $7 \mathrm{~d}$ injured sciatic nerve than in the ascending spinal cord PNG (Fig. $6 H$ ). Percentage of Importin $\beta 1$ mRNA containing axons were not significantly different between the naive sciatic nerve, $7 \mathrm{~d}$ injured sciatic nerve, or ascending spinal cord PNG (Fig. $6 H$ ).

With this differential increase in the PNG for axons containing Reg3a versus Hamp mRNAs, we asked whether the mRNAs for other RAGs known to be transported into regenerating PNS axons might also localize into these regenerating CNS axons. 

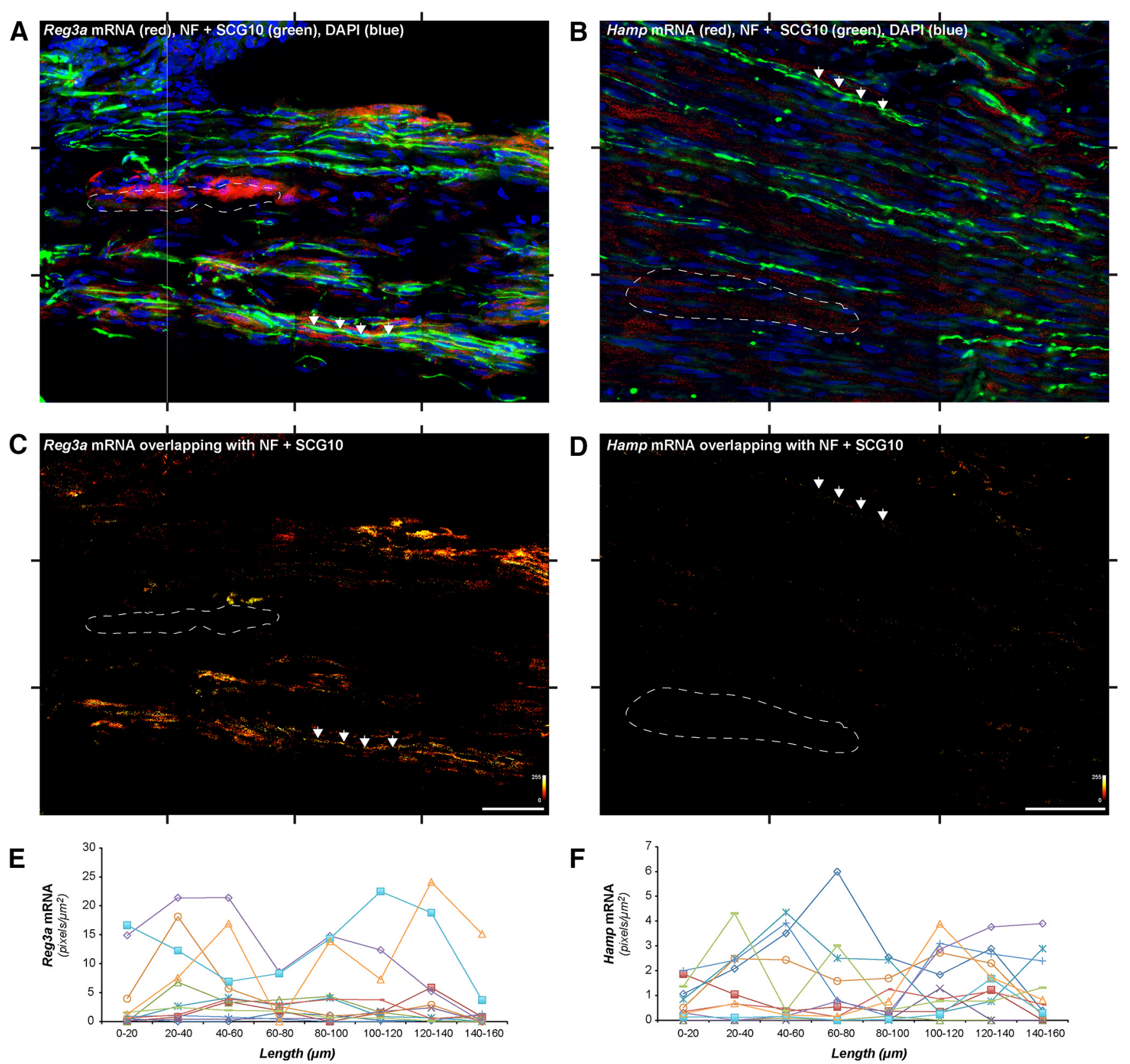

Figure 5. Spatial distribution of axonal injury-induced mRNAs peripheral nerve grafted into a transected spinal cord. $\boldsymbol{A}-\boldsymbol{D}$, Representative montage tile images from spinal cord ascending PNG at $21 \mathrm{~d}$ after transection and grafting are shown. $\boldsymbol{A}$ and $\boldsymbol{B}$ show merged Rega $(\boldsymbol{A})$ and Hamp (B) mRNAs (red) merged with NF plus SCG10 protein (green) to highlight regenerating axons and DAPI (blue) to detect Schwann cell nuclei. Arrows indicate axonal RNA, and the dotted region shows RNA signals that are clearly not overlapping with NF plus SCG10 signals. These images were processed to subtract the RNA FISH signals overlapping with NF plus SCG10 immunoreactivity to derive a subtracted axon-only channel. $\mathbf{C}$ and $\boldsymbol{D}$ show the xyz projections of the subtracted axon-only signals in the PNG for Reg3a $(\boldsymbol{C})$ and $\operatorname{Hamp}(\boldsymbol{D})$ mRNAs. Arrows and dotted region correspond to those same areas highlighted in $\boldsymbol{A}$ and $\boldsymbol{B}$. The xyz projections were generated from 12 optical sections taken at $0.29 \mu \mathrm{m} Z$ step intervals. Scale bars, $50 \mu \mathrm{m}$. $\boldsymbol{E}, \boldsymbol{F}$, Quantification of pixel intensity for Reg3a $(\boldsymbol{E})$ and $\operatorname{Hamp}(\boldsymbol{F}) \mathrm{mRNA}$ FISH signals across individual axons (160 $\mu \mathrm{m}$ contiguous lengths, $n=12$ ) is shown with intensities considered in $20 \mu \mathrm{m}$ bins across each axon. Signal intensities for each axon are displayed in a different color. There is substantial variation across $160 \mu \mathrm{m}$ length with "hotspots" of high signal intensity occurring in some axons separated by regions of much lower intensity.

GAP-43 is a well characterized RAG whose transcription increases during periods of axonal regeneration (Van der Zee et al., 1989). Nrn1 mRNA levels do not change overall after PNS nerve injury, but the mRNA shows increased localization into PNS axons after nerve crush injury (Merianda et al., 2013b). $\beta$-actin mRNA is likely the best characterized axonal mRNA, and the GFP transgene with the $3^{\prime}$ UTR of $\beta$-actin shows increased levels in ascending spinal cord axons after a thoracic contusion injury (Willis et al., 2011). We were able to detect each of these mRNAs in the PNG, and both $x y z$ and $y z$ projections confirmed axonal localization for GAP-43, Nrn1, and $\beta$-actin mRNAs in the PNG (Fig. $7 A-C$ ). The subtracted axon-only images showed clear granular FISH signals arrayed in linear profiles (Fig. $7 A-C$, bottom panels). Similar to Figure 6, quantitation of signal intensities did not show significant differences between the sciatic nerve and PNG samples, but there was substantial variability as we had seen with the other transcripts (Fig. $7 D-F$ ). However, assessing the percentage of mRNA-containing axons as outlined above showed significant differences. Significantly higher percentages of mRNA-containing axons was seen for all three mRNAs when 

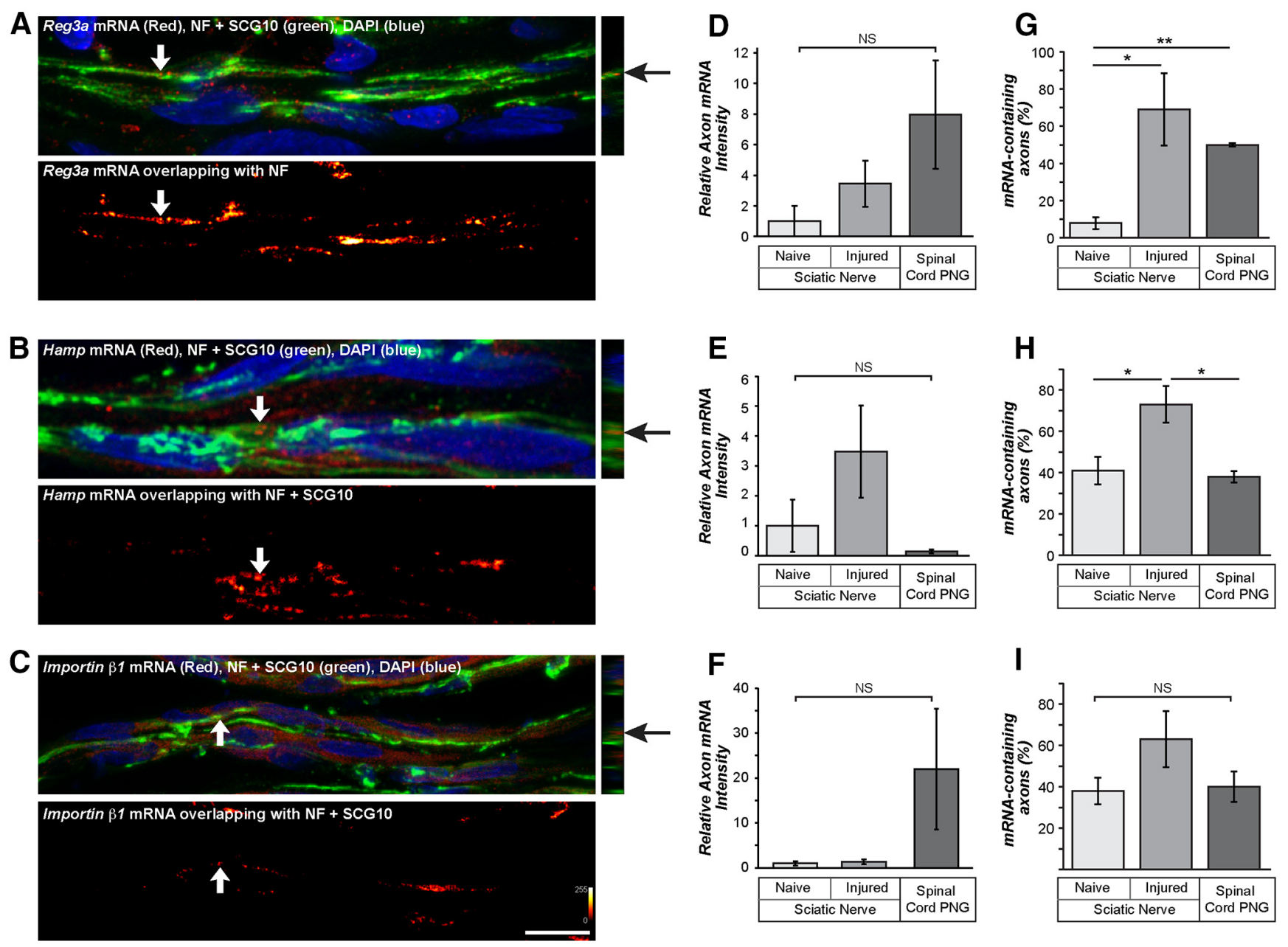

Figure 6. Reg3a, Hamp, and /mportin $\beta 1 \mathrm{mRNAs} \mathrm{show} \mathrm{differential} \mathrm{localization} \mathrm{in} \mathrm{sciatic} \mathrm{nerve} \mathrm{versus} \mathrm{spinal} \mathrm{cord} \mathrm{PNG.} A-C$, Representative confocal images of regenerating axons in an ascending spinal cord PNG with in situ hybridization for Reg3a (A), Hamp (B), and Importin $\beta 1$ (C) mRNAs and IF for NF plus SCG10 proteins. Each image set for $\boldsymbol{A}$ - $\boldsymbol{C}$ shows projected xyz with mRNA (red), axonal protein (green), and DAPI signals (blue) merged on the top left. The corresponding orthogonal yz projection is shown on the right. Subtracted axon-only mRNA signals are shown as an xyz projection on the bottom with RNA displayed as the indicated spectral image. $x y z$ projections were constructed from eight optical sections at $0.29 \mu \mathrm{m} Z$ step intervals. Optically isolated axon segments across the $Z$ stacks are indicated with arrows in the $x y z$ and $y z$ projections. Scale bar, $10 \mu \mathrm{m}$. D-F, Quantification of relative FISH signal intensity for the subtracted axon-only signals for Reg3a, Hamp, and Importin $\beta 1$ mRNAs is shown as indicated. Data are expressed as fold change compared with naive sciatic nerve \pm SEM ( $n \geq 50$ axons) across three biological replicates. NS, Not significant by one-way ANOVA. G-I, Quantification of the percentage of axons of $\geq 40 \mu \mathrm{m}$ length that contain Reg3a, Hamp, or Importin $\beta 1 \mathrm{mRNAs}$ is shown as indicated. Error bars indicate SEM ( $n \geq 50$ axons in 3 animals/group). ${ }^{*} p \leq 0.05,{ }^{* *} p \leq 0.001$. NS, Not significant by one-way ANOVA.

comparing the injured with naive sciatic nerves and ascending spinal cord PNG with naive sciatic nerve (Fig. $7 G-I$ ). The percentage of mRNA-containing axons was not significantly different between the PNGs and injured sciatic nerve samples for GAP-43, Nrn1, and $\beta$-actin. Together, our data indicate that axons regenerating from spinal cord into an ascending PNG contain RAG mRNAs that can be similar to that seen in the regenerating PNS.

\section{Axons regenerating into ascending PNG from injured spinal} cord contain translational machinery

Although the ascending axons in the spinal cord PNG clearly contain mRNAs, the data above did not provide evidence for use of these mRNAs as templates for protein synthesis. Thus, we asked whether the PNG axons contain ribosomes and translation factors that would be needed to synthesize proteins. We analyzed signals for phosphorylated epitope of the small ribosomal protein S6 and the 5.8S rRNA (using Y10B antibody) in axons of sciatic nerve and spinal cord PNGs by IF. For both antibodies, axonal and non-axonal signals were visible; nonetheless, the orthogonal $y z$ (Fig. 8, right insets) and subtracted axon-only (Fig. 8, bottom panels) channels showed unequivocal intra-axonal signals. The axon-only channels show focal aggregates of high signal intensities in the spectral images of the spinal cord PNG axons (Fig. $8 C, F$, bottom panels). The presence of both rRNA and phosphorylated $S 6$ protein suggest that translationally active ribosomes are present in the sciatic nerve and spinal cord PNG axons. The relative differences in signal intensity for phosphorylated S6 protein in these exposure-matched images suggest that the regenerating axons in the sciatic nerve and PNG contain translationally active ribosomes.

Translation factors have been demonstrated previously in injured PNS axons, so we asked whether the regenerating axons in the ascending spinal cord PNGs might contain proteins needed for initiation of translation. To address this, we used IF for 4EBP1 and eIF $2 \alpha$ that are needed for cap-dependent protein synthesis. Both 4EBP1 and eIF2 $\alpha$ immunoreactivities were detected in the axons of sciatic nerve and spinal cord PNGs (Fig. 9A-C,G-I). Again, orthogonal projections and subtracted axon-only channels confirmed intra-axonal signals for these translation 


\section{A}
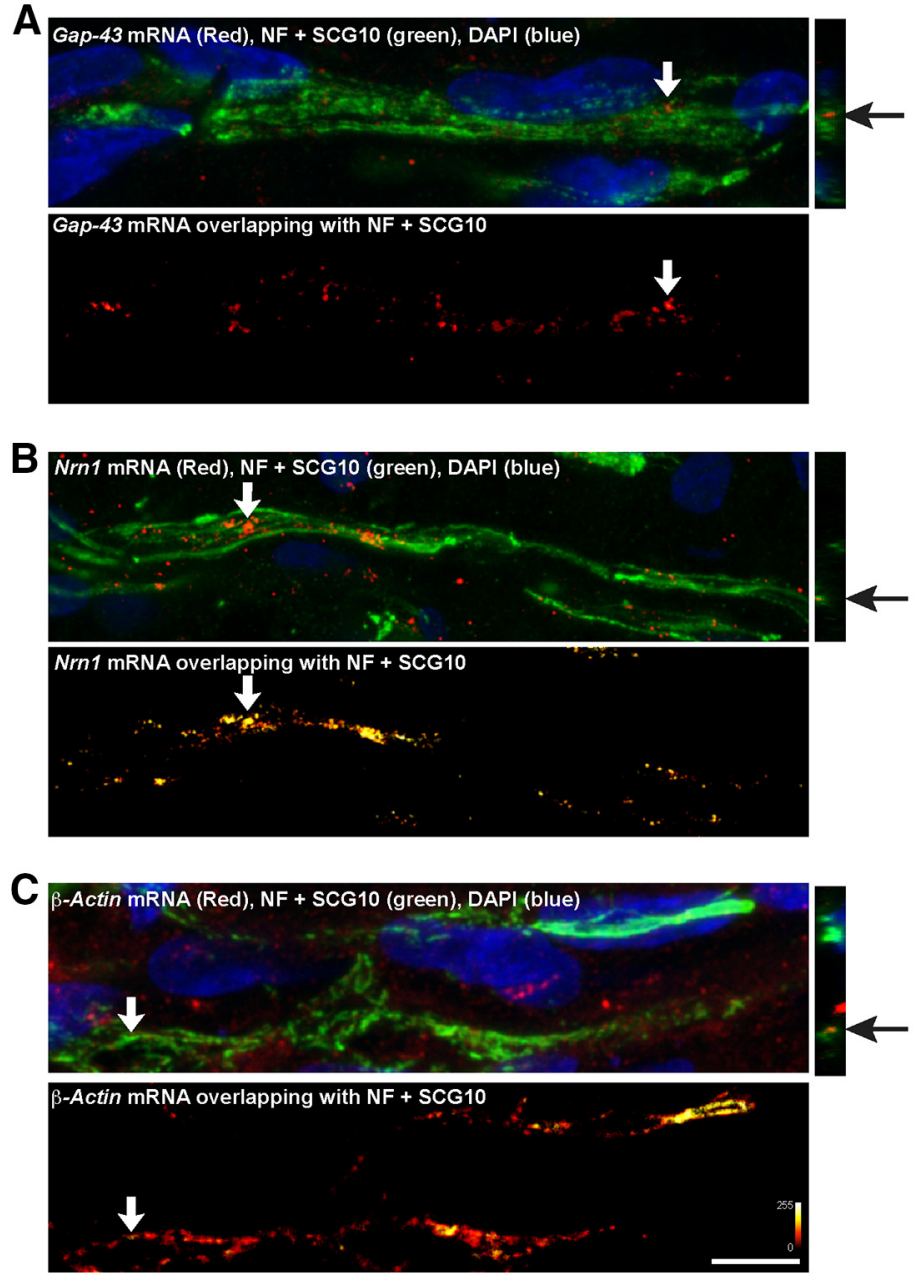
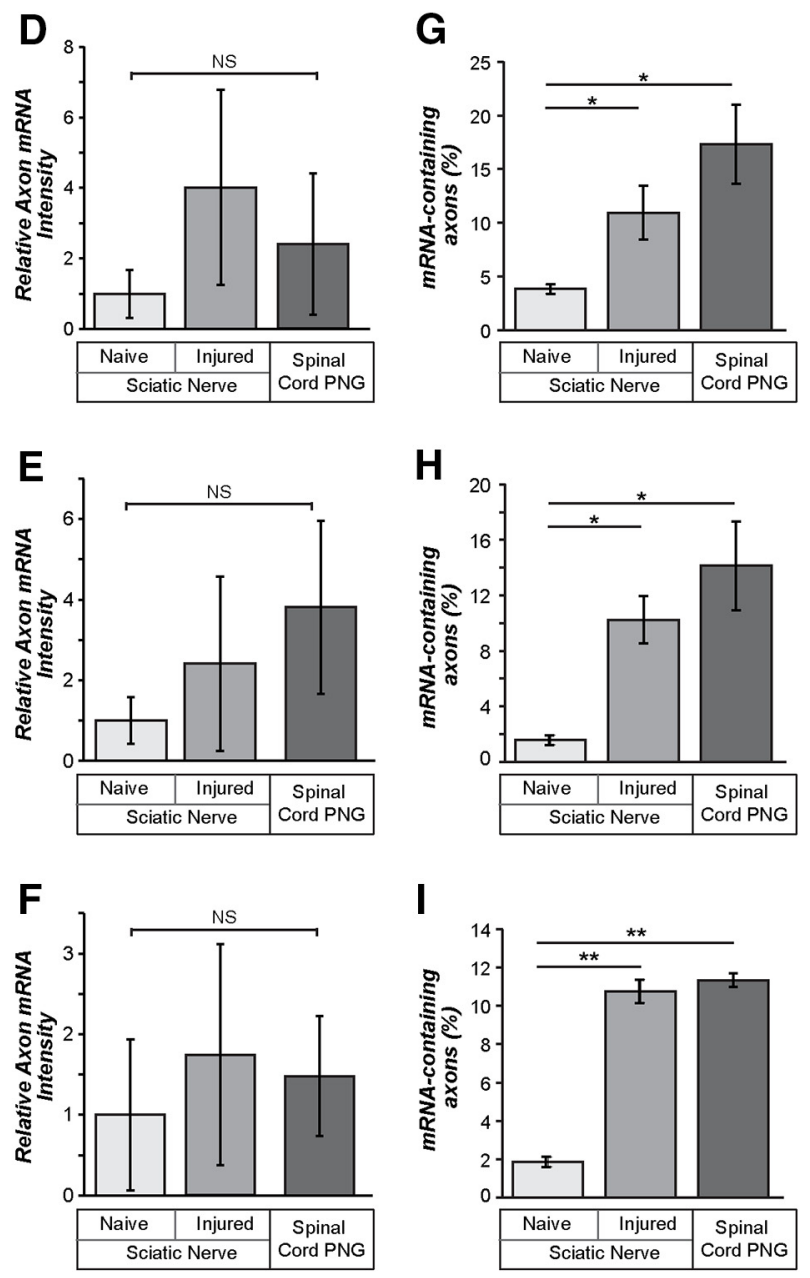

Figure 7. Axonal localization of growth-associated mRNAs in spinal cord axons regenerating into PNGs. $A-C$, Representative confocal images of regenerating axons in an ascending spinal cord PNG with in situ hybridization for GAP-43 (A), Nrn1 (B), and $\beta$-actin $(\boldsymbol{C})$ mRNAs plus IF for NF plus SCG10 proteins is shown as outlined in Figure $6 A--C$. xyz projections were constructed from eight optical sections at $0.29 \mu \mathrm{m} Z$ step intervals. Optically isolated axon segments across the $Z$ stacks are indicated with arrows in the $x y z$ and $y z$ projections. Scale bar, $10 \mu \mathrm{m}$. $D-I$, Quantification of relative FISH signal intensity intensities $(\boldsymbol{D}-\boldsymbol{F})$ and percentage of mRNA containing axons $(\boldsymbol{G}-\boldsymbol{I})$ is shown for the subtracted axon-only signals for $G A P-43(\boldsymbol{D}, \boldsymbol{G}), \operatorname{Nrn} 1(\boldsymbol{E}, \boldsymbol{H})$, and $\beta$-actin $(\boldsymbol{F}, \boldsymbol{I})$ mRNAs as per Figure 6D--I. Error bars represent SEM ( $n \geq 50$ axons in 3 animals/group). ${ }^{*} p \leq 0.05,{ }^{* *} p \leq 0.001$. NS, Not significant by one-way ANOVA.

machinery proteins. Activity of 4EPB1 and eIF2 $\alpha$ is regulated by phosphorylation, with phospho-4EBP1 promoting and phospho-eIF $2 \alpha$ attenuating cap-dependent protein synthesis (Raven and Koromilas, 2008). The phosphorylated epitopes for eIF2 $\alpha$ and 4 EBP 1 were similarly detected in the axons of sciatic nerve and the ascending spinal cord PNGs (Fig. $9 D-F, J-L$ ). The subtracted axon-only channels for phospho-eIF $2 \alpha$ showed relatively higher signals in the naive sciatic nerve compared with the $7 \mathrm{~d}$ crushed sciatic nerve and spinal cord PNG (Fig. $9 D$ vs $E, F)$. Conversely, the subtracted axon-only channels for phospho-4EBP1 showed relatively higher signals in the $7 \mathrm{~d}$ crushed sciatic nerve and ascending spinal cord PNG than naive sciatic nerve (Fig. $9 K, L$ vs $J$ ). Together, these data indicate that axons regenerating from spinal cord into the PNG likely have the capacity to use RAG mRNAs to locally generate proteins.

\section{Discussion}

Several laboratories have now shown that developing neurons can synthesize proteins in their axons and have implicated these intra-axonally synthesized proteins in axon pathfinding (Jung et al., 2012; Baleriola and Hengst, 2015). PNS neurons retain the capacity for intra-axonal protein synthesis into adulthood, and this localized mRNA translation is particularly robust after injury of peripheral nerves (Perry and Fainzilber, 2014). Although ribosomes were not visualized in mature CNS axons from early ultrastructural studies of hippocampus (Steward and Levy, 1982), mRNAs had been detected in axons of a few adult CNS neuron populations (Mohr et al., 1991; Wensley et al., 1995). This suggests that some mature CNS neurons could similarly retain the capacity to generate proteins in their axons. Very recent work from Baleriola et al. (2014) demonstrated that intra-axonal synthesis of rodent activating transcription factor 4 protein is activated in cortical neurons after injection of amyloid- $\beta \mathrm{A} \beta_{1-42}$ peptide into the hippocampus. Our data indicate that regenerating axons from the mature spinal cord may also have the potential to locally generate proteins when they are provided a PNG as a permissive environment for growth. The ascending spinal axons regenerating into a PNG contain mRNAs, ribosome constituents, and translation factors. Interestingly, axonal localization for some but not all of the RAG-encoded mRNAs studied here showed that the proportion of mRNA-containing axons in the PNG can be comparable with that of the regenerating peripheral nerve. These data are the first to show that endogenous 


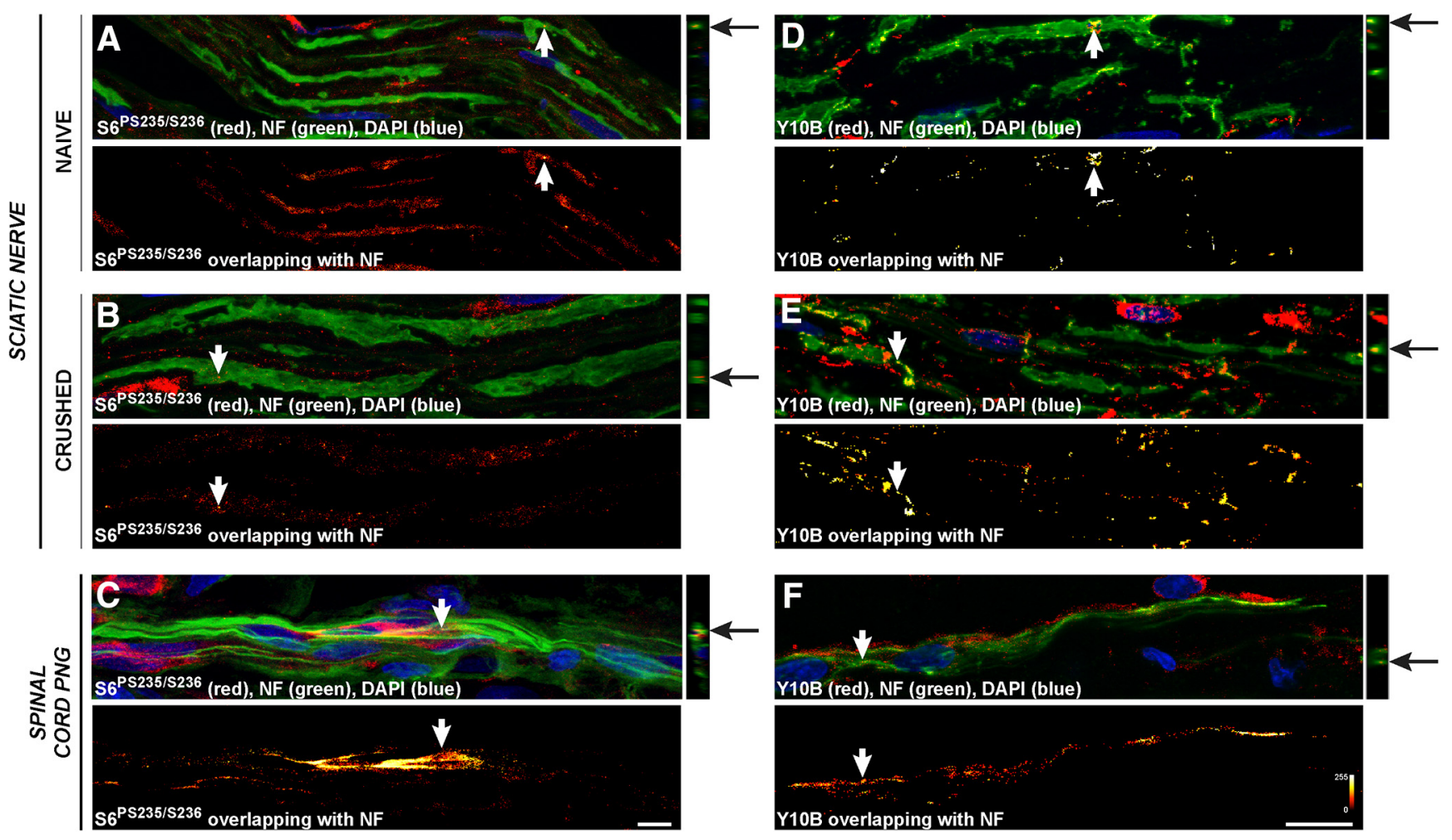

Figure 8. Axons regenerating into a spinal cord PNG contain components of ribosomes. Representative confocal images from naive sciatic nerve $(\boldsymbol{A}, \boldsymbol{D}), 7 \mathrm{~d}$ crushed sciatic nerve $(\boldsymbol{B}, \boldsymbol{E})$, and ascending spinal cord PNG $(\boldsymbol{C}, \boldsymbol{F})$ that were immunostained for phosphorylated ribosomal protein $\mathrm{S6}\left(\mathrm{S} 6^{\mathrm{PS} 235 / 5236} ; \boldsymbol{A}-\boldsymbol{C}\right)$ and 5.85 rRNA $(\mathrm{Y} 10 \mathrm{~B} ; \boldsymbol{D}-\boldsymbol{F})$ are shown. The series $\boldsymbol{A}-\boldsymbol{C}$ and $\boldsymbol{D}-\boldsymbol{F}$ are exposure-matched images with the top row of each showing xyz (left) and corresponding orthogonal yz projections (right) of merged channels for S6 ${ }^{\mathrm{PS} 235 / 5236}$ or Y10B (red), NF (green), and DAPI (blue). Bottom row of each image sequence shows the subtracted axon-only signals for $56^{\mathrm{P} 5235 / 5236}$ and $\mathrm{Y} 10 \mathrm{~B}$. Arrows in each panel represent the same axon segment that was isolated optically from non-neuronal elements above and below the axoplasm in the planes used for xyz projection. These projections were generated from 10 optical sections taken at $0.29 \mu \mathrm{m} Z$ step intervals. Scale bars, $10 \mu \mathrm{m}$.

mRNAs can be transported into the axons regenerating within the mature mammalian spinal cord.

Localization of mRNAs into ascending spinal cord PNG axons would be of little use without access to translational machinery for synthesis of proteins. The localization of ribosome constituents and translation factors in the spinal cord PNG axons suggests that these axons can use the mRNAs to generate proteins, and the presence of phospho-4EBP1 in these axons further points to the capacity for cap-dependent translation as demonstrated previously for axons of cultured DRG neurons (Pacheco and Twiss, 2012). We showed previously that GFP protein accumulates in ascending spinal cord axons after spinal cord injury in transgenic mice expressing GFP mRNA that was axonally targeted using the $3^{\prime}$ UTR of $\beta$-actin mRNA; this was not the case in transgenic mice expressing a soma-restricted GFP plus $\gamma$-actin $3^{\prime}$ UTR mRNA (Willis et al., 2011). More direct evidence for translation in spinal cord axons was provided by Sinbis viral-mediated introduction of an exogenous reporter mRNA directly into spinal cord axons (Walker et al., 2012b). Together, these observations suggest that the mRNAs we visualized in the axons regenerating in PNGs are likely to be used for protein synthesis.

Although the absolute pixel intensities for the axonal mRNA signals did not give significant differences between the sciatic nerve and PNG samples, the percentage of mRNA-containing axons did show significant increases in regenerating versus naive sciatic nerve. For GAP-43, $\beta$-actin, and Nrn1 mRNAs, the percentage of mRNA-containing axons in the PNGs was comparable with the regenerating sciatic nerve, suggesting that a similar proportion of regenerating axons may have the capacity to synthesize proteins encoded by these mRNAs in the spinal cord PNG. Axonally synthesized $\beta$-actin, GAP-43, and NRN1 proteins have been shown to increase axon growth in adult DRG neurons (Donnelly et al., 2011, 2013; Merianda et al., 2013b). Each of these mRNAs, as well as Reg $3 a$ mRNA, showed a significantly higher percentage of mRNA-containing axons in the spinal cord PNG than in the naive sciatic nerve, suggesting that transport of these mRNAs into the regenerating PNG axons may be stimulated by activating growth programs in these neurons as we have seen for Nrn1 mRNA in PNS neurons (Merianda et al., 2013b). However, this is clearly not the case for all axonally localizing mRNAs, because Hamp and Importin $\beta 1$ mRNAs showed no difference in percentage of mRNA-containing axons when comparing the spinal cord PNG and naive sciatic nerve. Hamp, but not Importin $\beta 1$, mRNA showed increased percentage of mRNAcontaining axons in the crushed compared with the naive sciatic nerve. The increase in Reg3a and Hamp mRNAs in the L4-L5 DRGs after sciatic nerve injury and the axonal localization of these gene products suggest that they represent RAGs similar to GAP-43, Nrn1, and $\beta$-actin mRNAs. Interestingly, expression of Reg3a and Hamp mRNAs after PNS crush injury is regulated by Stat $3 \alpha$ that is generated locally in PNS axons shortly after axon crush and retrogradely transported (Ben-Yaakov et al., 2012). The locally synthesized Importin $\beta 1$ protein also forms a retrograde signaling complex after PNS axotomy (Hanz et al., 2003; Perry et al., 2012), so the comparable levels of Importin $\beta 1 \mathrm{mRNA}$ in the PNG axons versus naive and crushed sciatic nerve axons may point to a similar function in the CNS. 

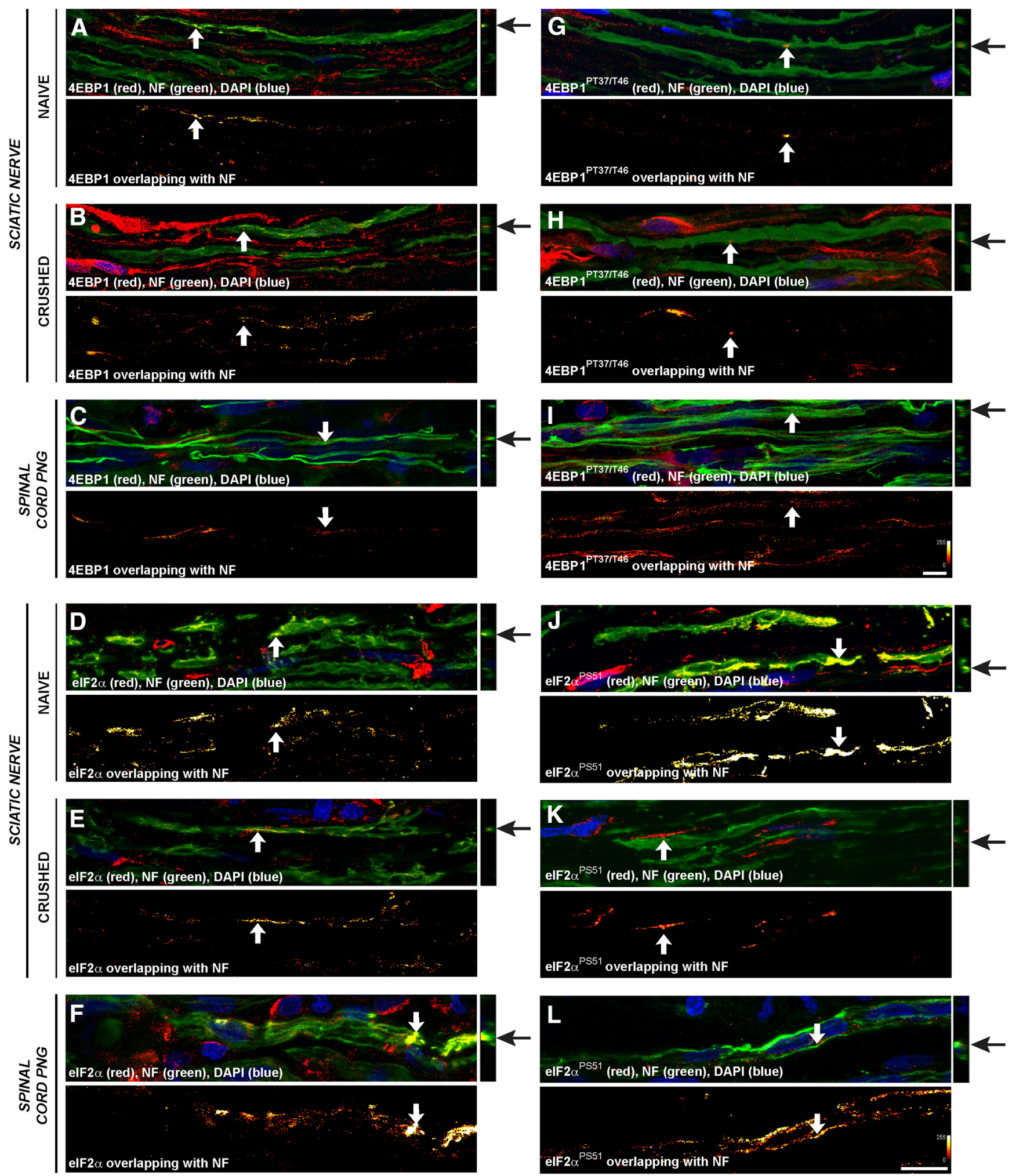

Figure 9. Axons regenerating into a spinal cord PNG contain elF2 $\alpha$ and 4EBP1. Representative confocal images from naive sciatic nerve $(\boldsymbol{A}, \boldsymbol{D}, \boldsymbol{G}, J), 7 \mathrm{~d}$ crushed sciatic nerve $(\boldsymbol{B}, \boldsymbol{E}, \boldsymbol{H}$, $\boldsymbol{K})$, and ascending spinal cord PNG $(\boldsymbol{C}, \boldsymbol{F}, \boldsymbol{I}, \boldsymbol{L})$ that were immunostained for 4EBP1 $(\boldsymbol{A}-\boldsymbol{C})$, phospho-4EBP1 $\left(4 \mathrm{EBP} 1^{\mathrm{PT3} 7 / \mathrm{T} 46} ; \boldsymbol{G}-\boldsymbol{I}\right)$, elF2 $\alpha(\boldsymbol{D}-\boldsymbol{F})$, and phospho-elF2 $\alpha\left(\mathrm{elF} 2 \alpha^{\text {PS51 }} ; \boldsymbol{J}-\boldsymbol{L}\right)$ are shown. $x y z$ and orthogonal $y z$ projections in the top row of each image sequence with 4 EBP1 and elF $2 \alpha$ in red, NF protein in green, and DAPI signal in blue. The bottom row of each image sequence shows xyz projection of subtracted axon-only signals for 4EBP1 and elF $2 \alpha$ as the indicated intensity spectrum. Arrows in each panel represent the same axon segment that was isolated optically from non-neuronal elements above and below the axoplasm in the planes used for xyz projection. These projections were generated from 10 optical sections taken at $0.29 \mu \mathrm{m} Z$ step intervals. Scale bar, $10 \mu \mathrm{m}$. 
Reg3a and Hamp mRNAs were reported to be transcriptionally regulated after PNS and CNS axotomy (Ben-Yaakov et al., 2012; Blesch et al., 2012), but neither have been defined as RAGs. The coupling of increased transcription and axonal mRNA localization for Reg3a and Hamp mRNAs is reminiscent of the well characterized RAG GAP-43 mRNA (Benowitz and Routtenberg, 1997). However, it is not clear whether the proteins encoded by Reg3a and Hamp contribute to axon growth. Reg3a is a member of the regenerating islet-derived protein family that encode lectin-related secretory proteins (Zhang et al., 2003). Reg3a has also been called pancreatitis-associated protein II because its expression is induced in the early phase of pancreatitis and the protein is thought to contribute to tissue repair (Honda et al., 2002; Zhang et al., 2003). Hamp mRNA encodes the Hepcidin peptide; hepatocyte-generated Hepicidin contributes to plasma iron homeostasis, but the protein is also widely expressed in brain and is induced by inflammatory stimuli (Zhang et al., 2003; Zechel et al., 2006; Wang et al., 2010). Indeed, LPS induces Hepcidin in cortical neurons cocultured with microglia, a mechanism that was linked to IL-6 from microglia activating neuronal Stat3 signaling (Qian et al., 2014). The post-axotomy increases in Reg3a and Hamp mRNAs could be triggered by inflammation, but the contributions of these proteins to axon growth will require additional studies.

Both transport and translation of mRNAs in axons have been shown to be regulated by extracellular stimuli, including stimuli that are chemotactic for axons (Hüttelmaier et al., 2005; Willis et al., 2007; Cox et al., 2008; Tcherkezian et al., 2010; Walker et al., 2012a). The varying distributions of mRNA aggregates along individual axons shown in Figure 5 for the PNGs was comparable with that seen in the sciatic nerve samples. Previous ultrastructural analyses of myelinated PNS axons indicated a periaxoplasmic distribution for ribosomes in domains spaced at 11-35 $\mu \mathrm{m}$ intervals in extruded axoplasm preparations (Koenig et al., 2000), which is comparable with the frequency distributions seen for mRNAs along some of the regenerating PNG axons (Fig. 5). More recent work has indicated that $\beta$-actin mRNA and the zip code binding protein 1 (ZBP1) RNA binding protein needed for its axonal localization also localize to these peri-axoplasmic ribosome plaques in myelinated PNS axons (Koenig, 2009). Similar clustering of $\beta$-actin mRNA, ZBP1, and ribosomes has been reported for sites of branching along axons of cultured DRG neurons (Spillane et al., 2011, 2013). The immunostaining for rRNA with Y10B antibody and the ribosomal protein S6 in the sciatic nerve and PNG could represent periaxoplasmic ribosome plaques in these axons. However, additional studies will be needed to determine whether these aggregates of mRNA and translational machinery represent foci of active intra-axonal translation or materials in transit to the growth cone.

The transport of mRNAs into the PNG axons is modulated at the level of individual mRNAs, similar to what we and others have documented previously for the injured and regenerating peripheral nerve (Gomes et al., 2014). In cultured neurons, neonatal and adult DRG neurons show different mRNA populations and can alter their axonal transcriptome after axotomy (Taylor et al., 2009; Gumy et al., 2011). Growth-promoting and growthinhibiting stimuli also alter the transcriptome of the axon (Willis et al., 2007). The different axonal mRNA localization between the spinal cord axons regenerating into the PNG and those in the sciatic nerve may relate to differences in growth capacity of these neurons or to stimuli in the extracellular environment that they traverse. The axons regenerating into the ascending PNGs used here include central branches from both DRGs and spinal cord interneurons (data not shown); future studies will be needed to distinguish these neuronal populations at the mRNA level. Regardless of any differences in localization, our data indicate that axonal transport and likely translation can be activated in the CNS when the axons are facilitated in their regenerative effort. Thus, the PNG likely provides a supportive environment for both growth and intra-axonal translation. The increased localization of RAG encoding mRNAs raises the possibility that axonal mRNA transport and/or localized translation could be targeted for increasing CNS axon growth and guidance toward appropriate target areas.

\section{References}

Baleriola J, Hengst U (2015) Targeting axonal protein synthesis in neuroregeneration and degeneration. Neurotherapeutics 12:57-65. CrossRef Medline

Baleriola J, Walker CA, Jean YY, Crary JF, Troy CM, Nagy PL, Hengst U (2014) Axonally synthesized ATF4 transmits a neurodegenerative signal across brain regions. Cell 158:1159-1172. CrossRef Medline

Benowitz LI, Routtenberg A (1997) GAP-43: an intrinsic determinant of neuronal development and plasticity. Trends Neurosci 20:84-91. CrossRef Medline

Ben-Yaakov K, Dagan SY, Segal-Ruder Y, Shalem O, Vuppalanchi D, Willis DE, Yudin D, Rishal I, Rother F, Bader M, Blesch A, Pilpel Y, Twiss JL, Fainzilber M (2012) Axonal transcription factors signal retrogradely in lesioned peripheral nerve. EMBO J 31:1350-1363. CrossRef Medline

Blesch A, Lu P, Tsukada S, Alto LT, Roet K, Coppola G, Geschwind D, Tuszynski MH (2012) Conditioning lesions before or after spinal cord injury recruit broad genetic mechanisms that sustain axonal regeneration: superiority to camp-mediated effects. Exp Neurol 235:162-173. CrossRef Medline

Côté MP, Amin AA, Tom VJ, Houle JD (2011) Peripheral nerve grafts support regeneration after spinal cord injury. Neurotherapeutics 8:294-303. CrossRef Medline

Cox LJ, Hengst U, Gurskaya NG, Lukyanov KA, Jaffrey SR (2008) Intraaxonal translation and retrograde trafficking of CREB promotes neuronal survival. Nat Cell Biol 10:149-159. CrossRef Medline

Donnelly CJ, Willis DE, Xu M, Tep C, Jiang C, Yoo S, Schanen NC, KirnSafran CB, van Minnen J, English A, Yoon SO, Bassell GJ, Twiss JL (2011) Limited availability of ZBP1 restricts axonal mRNA localization and nerve regeneration capacity. EMBO J 30:4665-4677. CrossRef Medline

Donnelly CJ, Park M, Spillane M, Yoo S, Pacheco A, Gomes C, Vuppalanchi D, McDonald M, Kim HH, Merianda TT, Gallo G, Twiss JL (2013) Axonally synthesized $\beta$-actin and GAP-43 proteins support distinct modes of axonal growth. J Neurosci 33:3311-3322. CrossRef Medline

Geoffroy CG, Zheng B (2014) Myelin-associated inhibitors in axonal growth after CNS injury. Curr Opin Neurobiol 27:31-38. CrossRef Medline

Gomes C, Merianda TT, Lee SJ, Yoo S, Twiss JL (2014) Molecular determinants of the axonal mRNA transcriptome. Dev Neurobiol 74:218-232. CrossRef Medline

Gumy LF, Yeo GS, Tung YC, Zivraj KH, Willis D, Coppola G, Lam BY, Twiss JL, Holt CE, Fawcett JW (2011) Transcriptome analysis of embryonic and adult sensory axons reveals changes in mRNA repertoire localization. RNA 17:85-98. CrossRef Medline

Hanz S, Perlson E, Willis D, Zheng JQ, Massarwa R, Huerta JJ, Koltzenburg M, Kohler M, van-Minnen J, Twiss JL, Fainzilber M (2003) Axoplasmic importins enable retrograde injury signaling in lesioned nerve. Neuron 40:1095-1104. CrossRef Medline

He SQ, Yao JR, Zhang FX, Wang Q, Bao L, Zhang X (2010) Inflammation and nerve injury induce expression of pancreatitis-associated protein-II in primary sensory neurons. Mol Pain 6:23. CrossRef Medline

Hellal F, Hurtado A, Ruschel J, Flynn KC, Laskowski CJ, Umlauf M, Kapitein LC, Strikis D, Lemmon V, Bixby J, Hoogenraad CC, Bradke F (2011) Microtubule stabilization reduces scarring and causes axon regeneration after spinal cord injury. Science 331:928-931. CrossRef Medline

Honda H, Nakamura H, Otsuki M (2002) The elongated PAP II/Reg III mRNA is upregulated in rat pancreas during acute experimental pancreatitis. Pancreas 25:192-197. CrossRef Medline

Hüttelmaier S, Zenklusen D, Lederer M, Dictenberg J, Lorenz M, Meng X, 
Bassell GJ, Condeelis J, Singer RH (2005) Spatial regulation of betaactin translation by Src-dependent phosphorylation of ZBP1. Nature 438: 512-515. CrossRef Medline

Jung H, Yoon BC, Holt CE (2012) Axonal mRNA localization and local protein synthesis in nervous system assembly, maintenance and repair. Nat Rev Neurosci [Erratum (2012) 13:597] 13:308-324. CrossRef Medline

Kindler S, Mohr E, Richter D (1997) Quo vadis: extrasomatic targeting of neuronal mRNAs in mammals. Mol Cell Endocrinol 128:7-10. CrossRef Medline

Koenig E (2009) Organized ribosome-containing structural domains in axons. Results Probl Cell Diff 48:173-191. CrossRef Medline

Koenig E, Martin R, Titmus M, Sotelo-Silveira JR (2000) Cryptic peripheral ribosomal domains distributed intermittently along mammalian myelinated axons. J Neurosci 20:8390-8400. Medline

Liu K, Lu Y, Lee JK, Samara R, Willenberg R, Sears-Kraxberger I, Tedeschi A, Park KK, Jin D, Cai B, Xu B, Connolly L, Steward O, Zheng B, He Z (2010) PTEN deletion enhances the regenerative ability of adult corticospinal neurons. Nat Neurosci 13:1075-1081. CrossRef Medline

Martin KC, Ephrussi A (2009) mRNA localization: gene expression in the spatial dimension. Cell 136:719-730. CrossRef Medline

Merianda TT, Vuppalanchi D, Yoo S, Blesch A, Twiss JL (2013a) Axonal transport of neural membrane protein 35 mRNA increases axon growth. J Cell Sci 126:90-102. CrossRef Medline

Merianda TT, Gomes C, Yoo S, Vuppalanchi D, Twiss JL (2013b) Axonal localization of neuritin/CPG15 mRNA in neuronal populations through distinct 5' and 3' UTR elements. J Neurosci 33:13735-13742. CrossRef Medline

Mohr E, Fehr S, Richter D (1991) Axonal transport of neuropeptide encoding mRNAs within the hypothalamo-hypophysial tract of rats. EMBO J 10:2419-2424. Medline

Pacheco A, Twiss JL (2012) Localized IRES-dependent translation of ER chaperone protein mRNA in sensory axons. PLoS One 7:e40788. CrossRef Medline

Park KK, Liu K, Hu Y, Smith PD, Wang C, Cai B, Xu B, Connolly L, Kramvis I, Sahin M, He Z (2008) Promoting axon regeneration in the adult CNS by modulation of the PTEN/mTOR pathway. Science 322:963-966. CrossRef Medline

Perry RB, Fainzilber M (2014) Local translation in neuronal processes-in vivo tests of a "heretical hypothesis." Dev Neurobiol 74:210-217. CrossRef Medline

Perry RB, Doron-Mandel E, Iavnilovitch E, Rishal I, Dagan SY, Tsoory M, Coppola G, McDonald MK, Gomes C, Geschwind DH, Twiss JL, Yaron A, Fainzilber M (2012) Subcellular knockout of Importin $\beta 1$ perturbs axonal retrograde signaling. Neuron 75:294-305. CrossRef Medline

Qian ZM, He X, Liang T, Wu KC, Yan YC, Lu LN, Yang G, Luo QQ, Yung WH, Ke Y (2014) Lipopolysaccharides upregulate hepcidin in neuron via microglia and the IL-6/STAT3 signaling pathway. Mol Neurobiol 50: 811-820. CrossRef Medline

Raven JF, Koromilas AE (2008) PERK and PKR: old kinases learn new tricks. Cell Cycle 7:1146-1150. CrossRef Medline

Spillane M, Ketschek A, Jones SL, Korobova F, Marsick B, Lanier L, Svitkina T, Gallo G (2011) The actin nucleating Arp2/3 complex contributes to the formation of axonal filopodia and branches through the regulation of actin patch precursors to filopodia. Dev Neurobiol 71:747-758. CrossRef Medline

Spillane M, Ketschek A, Merianda TT, Twiss JL, Gallo G (2013) Mitochondria coordinate sites of axon branching through localized intra-axonal protein synthesis. Cell Rep 5:1564-1575. CrossRef Medline

Steward O, Levy WB (1982) Preferential localization of polyribosomes un- der the base of dendritic spines in granule cells of the dentate gyrus. J Neurosci 2:284-291. Medline

Sun F, Park KK, Belin S, Wang D, Lu T, Chen G, Zhang K, Yeung C, Feng G, Yankner BA, He Z (2011) Sustained axon regeneration induced by codeletion of PTEN and SOCS3. Nature 480:372-375. CrossRef Medline

Taylor AM, Berchtold NC, Perreau VM, Tu CH, Li Jeon N, Cotman CW (2009) Axonal mRNA in uninjured and regenerating cortical mammalian axons. J Neurosci 29:4697-4707. CrossRef Medline

Tcherkezian J, Brittis PA, Thomas F, Roux PP, Flanagan JG (2010) Transmembrane receptor DCC associates with protein synthesis machinery and regulates translation. Cell 141:632-644. CrossRef Medline

Twiss JL, van Minnen J (2006) New insights into neuronal regeneration: the role of axonal protein synthesis in pathfinding and axonal extension. J Neurotrauma 23:295-308. CrossRef Medline

Twiss JL, Smith DS, Chang B, Shooter EM (2000) Translational control of ribosomal protein L4 is required for rapid neurite extension. Neurobiol Dis 7:416-428. CrossRef Medline

Van der Zee CE, Nielander HB, Vos JP, Lopes da Silva S, Verhaagen J, Oestreicher AB, Schrama LH, Schotman P, Gispen WH (1989) Expression of growth-associated protein B-50 (GAP43) in dorsal root ganglia and sciatic nerve during regenerative sprouting. J Neurosci 9:3505-3512. Medline

Verma P, Chierzi S, Codd AM, Campbell DS, Meyer RL, Holt CE, Fawcett JW (2005) Axonal protein synthesis and degradation are necessary for efficient growth cone regeneration. J Neurosci 25:331-342. CrossRef Medline

Vuppalanchi D, Coleman J, Yoo S, Merianda TT, Yadhati AG, Hossain J, Blesch A, Willis DE, Twiss JL (2010) Conserved 3'-untranslated region sequences direct subcellular localization of chaperone protein mRNAs in neurons. J Biol Chem 285:18025-18038. CrossRef Medline

Walker BA, Ji SJ, Jaffrey SR (2012a) Intra-axonal translation of RhoA promotes axon growth inhibition by CSPG. J Neurosci 32:14442-14447. CrossRef Medline

Walker BA, Hengst U, Kim HJ, Jeon NL, Schmidt EF, Heintz N, Milner TA, Jaffrey SR (2012b) Reprogramming axonal behavior by axon-specific viral transduction. Gene Ther 19:947-955. CrossRef Medline

Wang SM, Fu LJ, Duan XL, Crooks DR, Yu P, Qian ZM, Di XJ, Li J, Rouault TA, Chang YZ (2010) Role of hepcidin in murine brain iron metabolism. Cell Mol Life Sci 67:123-133. CrossRef Medline

Wensley CH, Stone DM, Baker H, Kauer JS, Margolis FL, Chikaraishi DM (1995) Olfactory marker protein mRNA is found in axons of olfactory receptor neurons. J Neurosci 15:4827-4837. Medline

Willis DE, van Niekerk EA, Sasaki Y, Mesngon M, Merianda TT, Williams GG, Kendall M, Smith DS, Bassell GJ, Twiss JL (2007) Extracellular stimuli specifically regulate localized levels of individual neuronal mRNAs. J Cell Biol 178:965-980. CrossRef Medline

Willis DE, Xu M, Donnelly CJ, Tep C, Kendall M, Erenstheyn M, English AW, Schanen NC, Kirn-Safran CB, Yoon SO, Bassell GJ, Twiss JL (2011) Axonal Localization of transgene mRNA in mature PNS and CNS neurons. J Neurosci 31:14481-14487. CrossRef Medline

Yoo S, Kim HH, Kim P, Donnelly CJ, Kalinski AL, Vuppalanchi D, Park M, Lee SJ, Merianda TT, Perrone-Bizzozero NI, Twiss JL (2013) A HuDZBP1 ribonucleoprotein complex localizes GAP-43 mRNA into axons through its $3^{\prime}$ untranslated region AU-rich regulatory element. J Neurochem 126:792-804. CrossRef Medline

Zechel S, Huber-Wittmer K, von Bohlen und Halbach O (2006) Distribution of the iron-regulating protein hepcidin in the murine central nervous system. J Neurosci Res 84:790-800. CrossRef Medline

Zhang YW, Ding LS, Lai MD (2003) Reg gene family and human diseases. World J Gastroenterol 9:2635-2641. Medline 